\title{
Using Climate Change Scenarios to Evaluate Future Effectiveness of Potential Wetlands in Mitigating High Flows in a Midwestern U.S. Watershed
}

\author{
Kelli M. Walters ${ }^{1}$, Meghna Babbar-Sebens ${ }^{1,2}$ \\ ${ }^{1}$ School of Civil and Construction Engineering, Oregon State University, Corvallis, OR 97331, \\ USA \\ ${ }^{2}$ Corresponding Author: meghna@oregonstate.edu, 1-541-737-8536
}

\begin{abstract}
The Midwestern United States have seen increased flooding and droughts from climate change, urban development, deforestation, and wetlands removal. Adding new wetlands in the landscape have been proposed as a conservation strategy, especially in tile-drained agricultural watersheds, to increase upland storage of runoff and reduce peak flows. The goal of this study was to evaluate the long-term performance of a set of potential wetlands identified in the Eagle Creek Watershed in central Indiana, U.S., to reduce a range of high flows estimated from future climate scenarios. The Soil and Water Assessment Tool model was forced with bias-corrected climate projections from the North American Regional Climate Change Assessment Program to evaluate the impacts of climate change on watershed hydrology and peak flows. The ensemble of climate projections predicted both increase and decrease in magnitudes of the 5\% exceedance flow from the past (1971-2000) to the future (2041-2070) time period. However, the model predicted that if the potential wetlands existed in these time periods then the magnitude of the $5 \%$ exceedance flow would be reduced by approximately $0.5-1.5 \mathrm{~m}^{3} / \mathrm{s}$ across all climate projections and for both the past and future periods. These identified potential wetlands, which occupied only approximately $1.5 \%$ of the watershed area but received runoff from approximately $29 \%$ of the watershed area, were also found to reduce peak flows by up to $20-60 \mathrm{~m}^{3} / \mathrm{s}$ (i.e., $15-20 \%$ of the reference peak flows for a watershed without these wetlands). The wetlands were also found to decrease the frequency of high peak flows. Wetlands proved to be a robust solution for peak flow reduction, producing consistent reductions from the past to future time periods and across all climate projections. The methodology used in this study to incorporate climate change into hydrologic models to evaluate conservation practices could also be applied to other watersheds and other conservation practices for better long-term watershed management decisions.
\end{abstract}

Keywords: Wetlands, Hydrology, Climate change, NARCCAP, SWAT, Bias correction 


\section{INTRODUCTION}

The frequency of extreme rainfall events has increased over the last century in multiple regions of the world, and is predicted to continue to increase, causing increased flooding risks, erosion, and water quality degradation (U.S. Global Change Research Program, 2014; IPCC, 2014). Midwestern watersheds in the United States have already begun to see an increase in early spring runoff and peak flows, and can expect 10-20\% more runoff in 2041-2070 relative to 1971-2000 due to climate change (U.S. Global Change Research Program, 2014). In addition, multiple watersheds in Indiana and rest of Midwestern states have also experienced loss of diverse ecosystem services provided by watersheds because of land alterations, including deforestation, artificial agricultural drainage system, and urbanization. The climate and land use changes have resulted in an altered hydrologic cycle, as seen by earlier snow-melt runoff events, lower latesummer flows, more severe floods and droughts, and increased sediment and water quality problems. For example, in the year 2011 Indiana experienced record-breaking heat in 7 counties, record-breaking rainfall in 22 counties and record-breaking snowfall in 6 counties, resulting in a total of 12 broken heat records, 31 broken rainfall records, and 10 broken snowfall records (Natural Resources Defense Council (NRDC), 2012). The state has been declared a flooddisaster area 14 times between 2000 and 2011 from severe storms (Federal Emergency Management Agency (FEMA), 2014), where as in the period between 1989 and 1999 the state was declared only four times as flood disaster area. Based on current observations and climate change projections, the state can expect continued changes and worsening impacts (U.S. Global Change Research Program, 2014).

Restoration and construction of new wetlands have been proposed as alternatives to support existing structural solutions that mitigate flooding and regulate streamflows (Heisel, 2009; Hey, Kostel, \& Montgomery, 2009; Mitsch \& Day Jr., 2006; Wilson, 2009; Zedler, 2003). Hey et al. (2009) stated that restoration of wetlands in floodplains would provide additional storage for flood waters on the Mississippi River above Grafton, IL. They further reported that the 1993 flood would have filled $33 \%$ and the 2008 flood would have filled only $7 \%$ of the 100-year floodplain. In addition, the wetland area that would be needed to store the flood water from the 1993 flood would have only taken up only $4 \%$ of the total watershed area. Wetlands not only reduce peak streamflows by storing water away from the channel and slowly releasing it, but also 
improve water quality and provide wildlife habitat (Keddy, 2010; Moshiri, 1993). Heisel (2009) suggests an integrated management strategy to tie ecological restoration projects with flood control projects. Mitsch and Day Jr. (2006) found that constructing wetlands between farms and adjacent streams or diverting river water into wetlands along major channels in the MississippiOhio-Missouri River basin could also lead to substantial reductions in nitrogen loads in the river, in addition to providing flood control benefits. By restoring or constructing wetland areas, many of the long-term goals for this region could be met, including, increase in upland storage capacities, improvement in infiltration and groundwater recharge, reestablishment of natural flows, and improvements in water quality, wildlife habitat, and overall watershed health.

While the benefits of wetlands are well documented (Hey et al., 2009; Keddy, 2010; Mitsch \& Day Jr., 2006; Moshiri, 1993; Zedler, 2003), most existing climate-change related studies have investigated the negative impacts of climate change on existing wetlands. Using rule-based simulation models of hydrology and vegetation dynamics, studies have assessed how current stresses (such, as water quality issues) and man-made alterations (such as, drainage of wetlands for agriculture or construction or dikes and levees) will cause wetland functions to be more sensitive to climate change (Burkett \& Kusler, 2000; Poiani, Johnson, \& Kittel, 1995). Many studies have concluded that wetlands will likely see increased drying, reductions in wetland size, degradation of wetland habitat, increased demand for agriculture and irrigation water due to less available water, plants and wildlife species destruction, and gas emissions in future climates (Burkett \& Kusler, 2000; Johnson et al., 2005; Winter, 2000). The loss of wetlands due to future climate change will be challenging to contain (Hartig et al., 1997) and Hannah et al. (2002) advise that wetlands and protected areas will need to be supplemented with the creation of more wetland areas to withstand the effects of climate change and continue to provide streamflow management benefits.

However, there is a critical lack of research that evaluates how effective additional new wetlands on the landscape will be in mitigating impacts of expected extreme events (e.g., flooding and droughts) from changing climate, and how assessment methodologies incorporating climate change models and their results can be integrated into wetlands planning and management decisions. Previous research conducted in the Eagle Creek Watershed study area in Indiana (Babbar-Sebens et al., 2013) identified multiple potential wetland locations through which 
flooding benefits could be achieved via new restored/constructed wetlands. Babbar-Sebens et al. (2013) developed a GIS-based methodology for identifying possible upland wetland locations, and used a coupled hydrological model and optimization technique to optimize the spatial distribution of wetlands for upland storage and peak flow reductions. This study, however, used a hydrological model based on current climate input, providing shorter-term results and solutions. In a policy paper bringing light to the need to study how wetland restoration will change in future climates, Erwin (2009) encourages researchers to study wetlands in their spatial context within a watershed and stresses the importance of investigating climate change impacts when developing future wetland restoration initiatives. Erwin (2009) suggests a shift to using three-dimensional modeling techniques (e.g. MIKE SHE) to simulate integrated surface water, groundwater, land use, topographic and hydrological characteristics, and warns that if climate change and variability is not incorporated into medium and long range planning, the success of conservation plans will likely be reduced.

The study presented here evaluates the impacts of climate change on wetland management plans and develops a methodology for creating longer-term wetland restoration plans focused on flood mitigation benefits of wetlands. This research builds on the previous study by Babbar-Sebens et al. (2013) to examine how potential wetlands can be used to mitigate the expected impacts of climate change, but, as Erwin (2009) suggests, focuses on incorporating climate change into long range planning with wetlands. To assess wetland performance in future climate scenarios, the watershed was simulated using a hydrological model forced with climate data dynamically downscaled from an ensemble of global climate models. The main objective of this research was to assess the long term performance of potential wetlands in a Midwestern watershed in reducing peak stream flows in the future, based on available climate change data. Secondary goals for this study were to evaluate the use of climate projection data from the North American Regional Climate Change Assessment Program (NARCCAP) for use in hydrological impact modeling projects, assess urban development land use change impacts, and evaluate expected hydrological impacts of projected climate change in the test watershed. 


\section{DATA AND MODEL DESCRIPTION}

\subsection{Study Area}

Eagle Creek Watershed is primarily an agricultural watershed in Indiana. The Eagle Creek Watershed was selected for this study because of previous relevant work done in the area and supporting infrastructure for wetland planning. Extensive data has been collected for this area, multiple versions of hydrologic models have been developed and tested for the watershed, successful partnerships with stakeholders, including land owners, watershed alliance, federal and local agencies, exist, and an active program for long-term design of conservation practices is present.

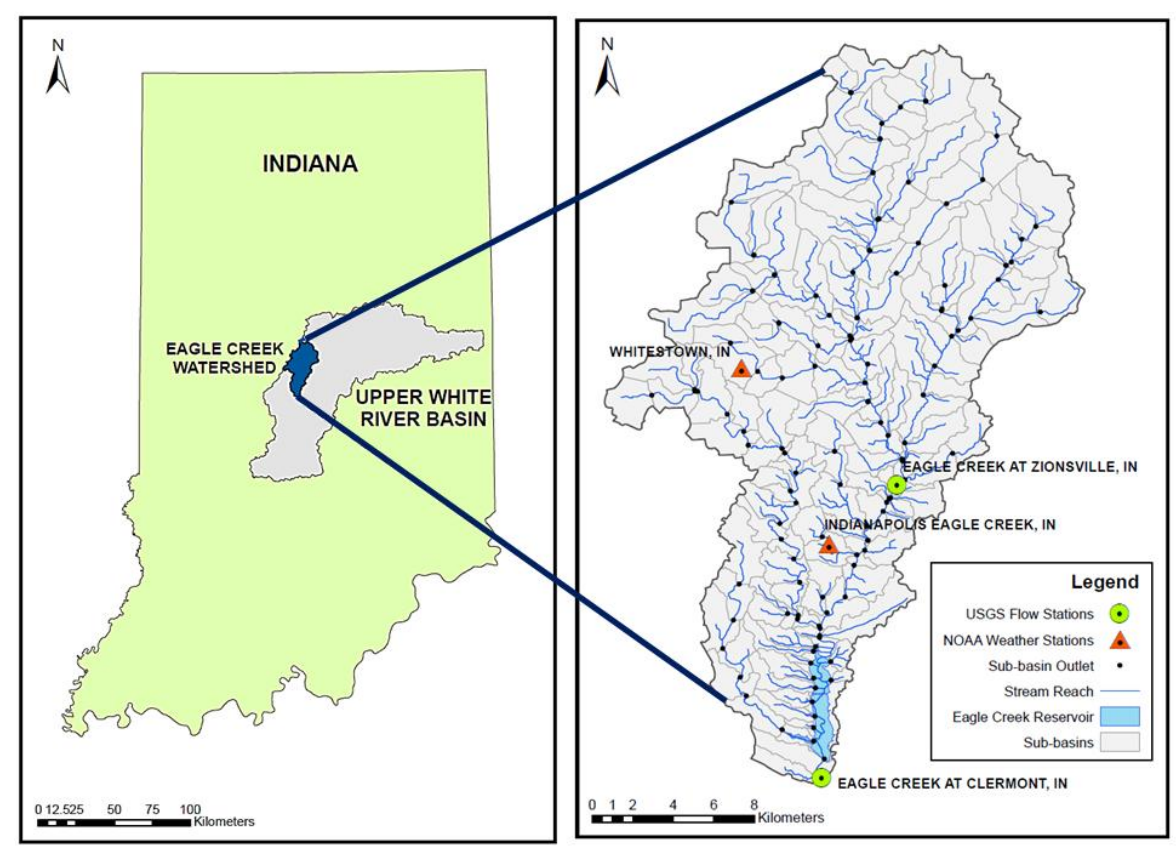

\section{Figure 1. Location of the Eagle Creek Watershed, IN.}

The Eagle Creek Watershed is located in central Indiana, about $16 \mathrm{~km}$ northwest of Indianapolis. It is part of the Upper White River Watershed and is located in Boone, Hamilton, Hendricks, and Marion counties. The watershed has a drainage area of about 420 square $\mathrm{km}$ and drains to the Eagle Creek Reservoir, which provides drinking water to Indianapolis, as well as serves recreational and flood control uses (Figure 1). The reservoir was constructed to mitigate the seasonal flood inundation in northwest Indianapolis, but has since become impaired by sediments, pesticides, and fertilizers from the agricultural land upstream (Piemonti et al., 2013). The watershed has been delineated into 130 sub-basins for modeling purposes, each containing 
an individual stream or channel reach connecting it to the next sub-basin. The topography of the land is flat to undulating, with elevations ranging from 240 to $299 \mathrm{~m}$ above sea level. The soils are generally productive soils developed in glacial till and loess. The primary land use for the watershed is agriculture (approximately 60\%, located in the northwest area of the watershed) with the main crops being corn and soybean. The southeast region has more urban development due to population growth in Indianapolis and increases in urban/suburban infrastructure.

The climate in Indiana is classified as continental, with high humidity, frequent changes in temperature and significant local precipitation (Clark, 1980). The average annual temperature is about $11.11^{\circ} \mathrm{C}$, with January typically being the coldest month and July typically begin the warmest. The average annual precipitation is around 96.5 to $101.6 \mathrm{~cm}$. About $59 \%$ of the precipitation occurs during the growing season of April through October, with May typically being the wettest month and February being the driest (Clark, 1980). Since 1980, the Midwest has already seen an increase of about $0.22^{\circ} \mathrm{C}$ in the average annual temperature (U.S. Global Change Research Program, 2014), bringing the average for Indiana up to $11.33^{\circ} \mathrm{C}$. By 2041 2070 , the average annual temperature is expected to increase by $2.1-2.3^{\circ} \mathrm{C}$ for the Indianapolis area (U.S. Global Change Research Program, 2014). The average annual precipitation is also expected to increase by $6.1-10.1 \mathrm{~cm}$ by $2041-2070$. Future climate trends for the area also include increases in high-intensity precipitation in spring, followed by hot, low-precipitation summers. These observed and projected increases in precipitation and temperature underscore the need for climate-informed surface water management, in order to minimize the impacts from resulting worse floods (Babbar-Sebens et al., 2013).

\subsection{Hydrology and Wetlands Model}

The hydrology of the study watershed and wetlands were simulated using the Soil and Water Assessment Tool (SWAT) model, which was developed by the United States Department of Agriculture (USDA) Agricultural Research Service (ARS) (Arnold et al., 1998; Neitsch, Arnold, Kiniry, \& Williams, 2011). The SWAT model is a continuous-time, physically based, distributed hydrologic model and can be parameterized and used through an ArcGIS interface (called ArcSWAT). The SWAT model was developed to simulate the impacts of land management practices on streamflow, water quality and chemical yields over long periods of time at a watershed or river basin scale. The SWAT model uses mechanistic and empirical sub-models 
and requires specific data input, including topography, land use, soil type and climate (Arnold et al., 1998; Neitsch et al., 2011). The most current version of the model (ArcSWAT 2012) was calibrated and used to simulate the hydrology and resulting streamflow in the Eagle Creek Watershed for this study.

To account for spatial distribution in basin characteristics and land management, the SWAT model divides the watershed into sub-basins connected by a stream network. Each sub-basin has one main flow channel or reach so that the outflow from one sub-basin flows into the next. The sub-basins are further divided into hydrologic response units (HRUs), which are unique combinations of land use land cover, soil type, and slope. The SWAT model performs water balance calculations individually for each HRU. The HRUs within a sub-basin do not interact with each other, but outputs from the HRUs are summed across HRUs in a sub-basin and routed through wetlands, reservoirs, ponds, and channels to the outlet. The hydrological cycle is separated into the land phase and the routing phase. The Soil Conservation Service (SCS) curve number method is used to compute runoff and channel routing uses the Muskingum routing method. The SWAT model calculates water quantity and water quality outputs, but only the streamflow output was used for this study.

The Eagle Creek Watershed SWAT model was built for a "current" time period, 2000-2012, and was run on a daily time step. The elevation data was input using a 10 meters (1/3 arc-second) digital elevation model (DEM) from the United States Geological Survey (USGS). A pre-defined watershed boundary with 130 sub-basins and stream network based on the topographic maps published by the USGS were used and for each sub-basin, the model calculates the outlet on the stream network based on the DEM. The USDA 2012 land use-land cover data from the Cropland Data Layer database and the USDA SSURGO soil data maps were input into the model. The 2012 land use map was used so that the calibrated model would reflect the most current land use and minimize the error when used for future predictions. Because the watershed is very flat, the slope was classified into three ranges, from $0-1 \%, 1-2 \%$ and $>2 \%$. From the slope classifications, land use, and soils, the HRUs were created with a $10 \%$ threshold, meaning that all land use, soil class, and slope class combination with less than $10 \%$ of sub-basin area coverage were eliminated. 
Daily observed climate data for precipitation and temperature was obtained from the National Oceanic and Atmospheric Administration (NOAA) stations at Whitestown, IN (station ID GHCND: USC00129557, latitude $39.996^{\circ}$, longitude $-86.354^{\circ}$ ) and at Indianapolis Eagle Creek, IN (station ID GHCND: USC00124249, latitude 39.920 , longitude $-83.313^{\circ}$ ). Observations were input for precipitation, minimum and maximum temperature, while the built-in weather generator in SWAT was used to simulate the relative humidity, wind speed, and solar radiation. For model calibration, the observed precipitation and temperature data from 2000-2012 were used and for the climate change analysis, climate model data (precipitation and temperature) were input for the time period being analyzed. Jha et al. (2006) conducted a climate change sensitivity assessment using SWAT for the Upper Mississippi River Basin (UMRB), which is predicted to have similar changes as the Ohio River Basin where this study is located (U.S. Global Change Research Program, 2014). In their study, they found that the future flows were most sensitive to precipitation and $\mathrm{CO}_{2}$ shifts, followed by increases in temperature, and that only minor impacts on future flow were found from changes in solar radiation and relative humidity. Because precipitation and temperature have the largest impact on streamflows, the weather generator was used for the relative humidity, wind speed, and solar radiation in all cases for this study. The reservoir bathymetry and daily water consumption was attained from the water utility (Indianapolis Water Co. now owned by Citizens Water). Dam releases were represented using daily flow measurements at the USGS Clermont station (station \#03353460). The Clermont station was used because data at the outlet station was unavailable and the Clermont station is located only $1.13 \mathrm{~km}$ downstream of the outlet and receives only $1.4 \%$ additional area (Babbar-Sebens et al., 2013). For calibration and evaluation, the modeled streamflow at the outlet of sub-basin 70 was compared to flow observations from the USGS station at Eagle Creek at Zionsville, IN (station \# 03353200).

Potential wetland locations for this watershed were identified in a study by Babbar-Sebens et al. (2013) using a GIS (Geographic Information Systems) based approach. Areas were selected as sites for potential wetland creation or restoration if the site had agricultural or related land use, poor soil drainage, and was located upland in areas that collect runoff. A total of 2953 potential sites for wetlands were originally identified to help reduce peak flows in streams, improve water quality, and provide wildlife habitat. The wetlands make up about $1.5 \%$ of the watershed area 
and receive runoff from approximately $29 \%$ of the watershed (Babbar-Sebens et al., 2013). In SWAT, wetlands are simulated as a water body located at the outlet of a sub-basin, meaning a maximum of one wetland per sub-basin is allowed. Due to this restriction and the large number of wetland polygons identified in every sub-basin, Babbar-Sebens et al. (2013) combined the area of all wetlands in a sub-basin into one large wetland, resulting in 108 potential wetlands at the outlets of their respective sub-basin. For the wetland module in SWAT, several wetland parameters were also estimated, including the fraction of sub-basin area that drains into the wetland, surface area of the wetland at maximum water level, volume of water stored in wetlands at maximum water level, initial volume of water in wetlands, and hydraulic conductivity through the bottom of the wetland. Babbar-Sebens et al. (2013) assumed an initial water volume of 0 for all wetlands, a water depth of $0.5 \mathrm{~m}$, and a hydraulic conductivity of $50 \mathrm{~mm} / \mathrm{h}$ (based on reported hydraulic conductivities of existing hydric soils in the watershed (Indiana soil survey reports, http://www.in.nrcs.usda.gov)).

\subsection{Climate Projection Data}

The climate projection data used was obtained from an ensemble of 8 models published by NARCCAP (Mearns et al., 2009). The NARCCAP climate projection datasets are created by running a set of atmosphere-ocean general circulation models (AOGCMs) that are dynamically downscaled using regional climate models (RCMs). Each dataset is named according to the RCM- AOGCM pair. The models used are described in Table 1. A few -RCM-AOGCM model output datasets available through NARCCAP were not used in this study due to data gaps and differences in calendars used. ECP2-HadCM3 and MM5I-HadCM3 were not used because they use a 360-day calendar and WRFG-CCSM was discarded because it contained large data gaps for the study area.

Table 1. NARCCAP climate projection models used.

\begin{tabular}{llllll}
\hline $\begin{array}{l}\text { RCM- } \\
\text { AOGCM }\end{array}$ & $\begin{array}{l}\text { Grid } \\
\text { Cell(s) } \\
(\mathbf{y c}, \mathbf{x c})\end{array}$ & Latitude & Longitude & $\begin{array}{l}\text { Date Range for } \\
\text { Past Data }\end{array}$ & $\begin{array}{l}\text { Date Range for } \\
\text { Future Data }\end{array}$ \\
\hline CRCM- & $(40,90)$, & 39.7908, & 273.604, & $12 / 1 / 1970-$ & $12 / 01 / 2040-$ \\
CCSM & $(41,90)$ & 40.1798 & 273.699 & $11 / 30 / 1999$ & $11 / 30 / 2070$ \\
CRCM- & $(40,90)$, & 39.7908, & 273.604, & $12 / 1 / 1970-$ & $12 / 01 / 2040-$
\end{tabular}




$\begin{array}{llllll}\text { CGCM3 } & (41,90) & 40.1798 & 273.699 & 11 / 30 / 2000 & 11 / 30 / 2070 \\ \text { HRM3- } & (49,96) & 40.0949 & 273.878 & 12 / 1 / 1970- & 12 / 01 / 2040- \\ \text { GFDL } & & & & 11 / 30 / 2000 & 11 / 30 / 2070 \\ \text { RCM3- } & (35,84), & 39.7791, & 273.472, & 12 / 1 / 1970- & 12 / 01 / 2040- \\ \text { CGCM3 } & (36,84) & 40.2213 & 273.551 & 11 / 30 / 2000 & 11 / 30 / 2070 \\ \text { RCM3- } & (35,84), & 39.7791, & 273.472, & 12 / 1 / 1970- & 12 / 01 / 2040- \\ \text { GFDL } & (36,84) & 40.2213 & 273.551 & 11 / 30 / 2000 & 11 / 30 / 2070 \\ \text { WRFG- } & (39,84) & 39.9825 & 273.617 & 12 / 1 / 1970- & 12 / 01 / 2040- \\ \text { CGCM3 } & & & & 11 / 30 / 2000 & 11 / 30 / 2070 \\ \text { MM5I- } & (34,79) & 39.9825 & 273.617 & 12 / 1 / 1970- & 12 / 01 / 2040- \\ \text { CCSM } & & & & 11 / 30 / 1998 & 11 / 30 / 2069 \\ \text { ECP2- } & (43,90), & 40.022, & 273.395, & 12 / 1 / 1970- & 12 / 01 / 2040- \\ \text { GFDL } & (43,91) & 39.949 & 273.902 & 11 / 30 / 2000 & 11 / 30 / 2070\end{array}$

The NARCCAP AOGCMs are based on the Intergovernmental Panel on Climate Change (IPCC) A2 emissions scenario (Nakicenovic \& Swart, 2000). In the Special Report on Emissions Scenarios (SRES), the IPCC outlined 4 families of emission scenarios - A1, A2, B1, and B2. Forty different emissions scenarios, grouped into the four families, were developed using possible changes in economic development, technological development, energy use, population change, and agriculture or land use change. The SRES states that all scenarios have the same likelihood of occurrence (Nakicenovic \& Swart, 2000). The A2 scenario is one of the higher emissions scenarios, and was selected for use by NARCCAP because it provides a larger change in modeling results and therefore leads to a more conservative design approach (Mearns, 2007). In the context of climate modeling and impact studies, a larger predicted change in climate will result in more dramatic hydrological results and if solutions are adapted to the more drastic effects, they can also adapt to smaller changes in climate. The A2 scenario family focuses on heterogeneity, self-reliance, and preservation of local identities. In the scenario, fertility patterns across regions converge slowly which results in the high population growth and the economic development is more regionalized. Compared to the other scenarios, the A2 scenario assumes that economic and technological developments are relatively slow, $\mathrm{CO}_{2}$ emissions are high, global average per capita income is low and population growth is rapid (Nakicenovic \& Swart, 2000).

NARCCAP covers the United States and most of Canada and the RCMs are run at a resolution of $50 \mathrm{~km}$ (Mearns, 2007). For each model, the RCM-AOGCM model output was obtained for the 
grid cell that contained most of the Eagle Creek Watershed, or the average of the RCM-AOGCM model output from two grid cells that both contained about half of the watershed. The location of each grid cell center-point in relation to the watershed is shown in Figure 2. NARCCAP produces RCM-AOGCM model outputs for two time periods: a past "hindcast" dataset from 1971-2000 and a "future period" dataset from 2041-2070. An almost 2-year spin-up period is removed from the data to account for the time it takes some model elements to equilibrate. The starting and ending dates for each model are shown in Table 1. The starting dates are one month prior to 1971 to allow for a full winter season, and for the same reason, the ending dates are one month prior to the end of the final year. The past period RCM-AOGCM model outputs were compared to observed data to evaluate how well the model represented the watershed historical climate and the future dataset was input into the hydrological model as climate projections, after applying the appropriate bias corrections, as discussed in later sections.

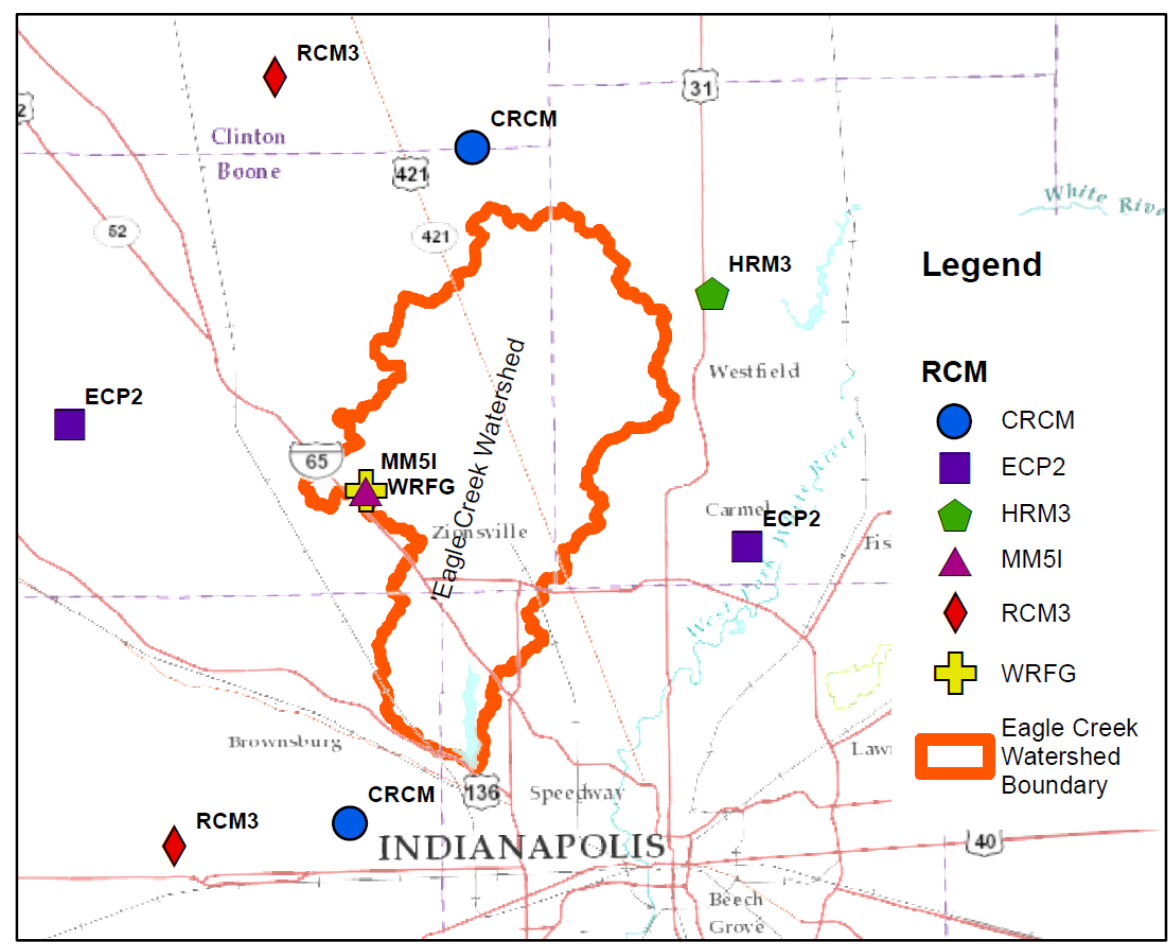

Figure 2. Map of NARCCAP grid cell center-point locations in relation to the Eagle Creek Watershed.

The climate variables used for this project were daily precipitation, minimum daily temperature, and maximum daily temperature. The precipitation RCM-AOGCM model outputs from the NARCCAP model runs are provided as a precipitation flux rate averaged over 3 hours, with units 
of $\mathrm{kg} / \mathrm{m}^{2} / \mathrm{s}$. To compare the precipitation flux to the observed daily precipitation values, the modeled precipitation flux was converted into a rainfall depth for each 3-hour increment and summed for each day. Assuming a water density of $1 \mathrm{~g} / \mathrm{cm}^{3}$, the flux is divided by the water density and assumed to be distributed evenly over 1 square meter, giving a rainfall depth per time. This value is then multiplied by 10800 seconds ( 3 hours) to calculate the total depth (in $\mathrm{mm}$ ) of precipitation over the 3 hours. The rainfall depths were then summed for every 24 hours to get a daily precipitation value. The temperature data are provided as daily values.

\section{METHODOLOGY}

This study was completed using the methodology outlined in Figure 3. Overview of modeling methodology

, which includes two concurrent analyses - a climate change analysis and a SWAT model analysis. The climate change data was analyzed by comparing the RCM-AOGCM output climate data for the historical period to observed data. Several bias correction methods were analyzed for the precipitation data and the best performing methods were applied to the RCM-AOGCM output data for the future time period. Concurrently, the SWAT model was developed for the watershed and then calibrated and evaluated against observed streamflow. In order to analyze the impacts of climate change on streamflow, the ensemble of bias corrected RCM-AOGCM model outputs was used as inputs into the calibrated SWAT model.

\section{CLIMATE CHANGE DATA ANALYSIS}

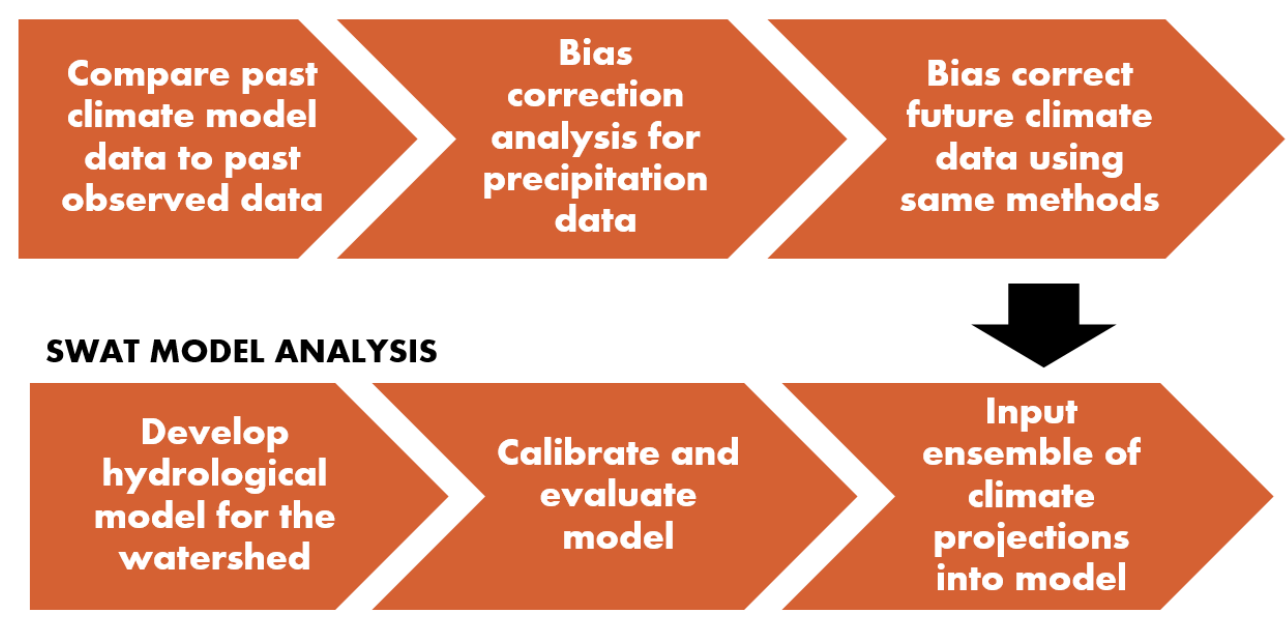

Figure 3. Overview of modeling methodology 


\subsection{Climate Data Analysis}

The hindcast NARCCAP RCM-AOGCM model outputs were compared to climate observations over the same time period to evaluate how well the models represent the observed climate in the watershed region. Although correlation between the model and historic data does not ensure accurate future predictions, confidence in the model will be increased if the hindcast RCMAOGCM model outputs adequately match the observed climate for the area. The minimum and maximum temperature RCM-AOGCM model outputs were evaluated using the long-term monthly mean. The square of the Pearson product moment correlation coefficient $\left(\mathrm{R}^{2}\right)$ was calculated for the modeled long-term monthly means when compared to the observed means. The RCM-AOGCM model output precipitation was evaluated using the long-term monthly mean, as well as the seasonal amplitude, annual precipitation, and long-term monthly coefficient of variation. The seasonal amplitude was calculated as the difference between the wettest and driest month each year. The annual precipitation was computed as the total precipitation in each year over the model period. The long-term monthly coefficient of variation was calculated as the coefficient of variation using all monthly precipitation for the respective month over the 19712000 period. These metrics were used to assess the RCM-AOGCM model outputs precipitation and confirm the need for bias corrections.

\subsubsection{Bias Correction Methods}

Climate models often produce a biased representation of observed climate (as seen for the precipitation in the climate data analysis results) and therefore, bias corrections were needed for the RCM-AOGCM model outputs. Biases in the climate model outputs can produce unrealistic results when used for hydrological modeling (Bergstrom et al., 2001), so it is necessary to force or correct the climate model outputs (Christensen et al., 2008). Climate models often struggle to accurately predict precipitation and will commonly overestimate the number of wet days with low-intensity precipitation, have biases in the mean, and have difficulty in predicting high precipitation events (Ines \& Hansen, 2006; Piani et al., 2010; Teutschbein \& Seibert, 2010).

In order to correct the potential biases in the RCM-AOGCM model output precipitation projections, the following bias correction methods (as presented in Teutschbein \& Seibert, 2012) were tested: (1) linear scaling, (2) local intensity scaling, (3) power transformation, and (4) distribution mapping. Each bias correction method is described in more detail in the following 
sections. The bias corrections were applied to the past daily RCM-AOGCM model outputs precipitation and were assumed to be stationary, meaning that the same bias corrections are still valid for the future data (Teutschbein \& Seibert, 2012). A list of variables and subscripts that apply to all bias correction equations is shown in Table 2.

Table 2. Definition of variables used in text and equations.

\begin{tabular}{cl}
\hline Variable & Definition \\
\hline $\boldsymbol{\alpha}$ & Shape parameter of Gamma distribution \\
$\boldsymbol{b}_{\boldsymbol{m}}$ & Long-term monthly exponential parameter \\
$\boldsymbol{\beta}$ & Scale parameter of Gamma distribution \\
$\boldsymbol{C} \boldsymbol{V}_{\boldsymbol{m}}$ & Long-term monthly coefficient of \\
& variation \\
$\boldsymbol{f}_{\boldsymbol{\gamma}}$ & Probability distribution function \\
$\boldsymbol{F}_{\boldsymbol{\gamma}}$ & Cumulative distribution function \\
$\boldsymbol{F}_{\boldsymbol{\gamma}}^{-\mathbf{1}}$ & Inverse of cumulative distribution \\
& function \\
$\boldsymbol{\Gamma}$ & Gamma function \\
$\boldsymbol{\mu}_{\boldsymbol{m}}$ & Long-term monthly mean \\
$\boldsymbol{P}^{*}$ & Final bias corrected precipitation \\
$\boldsymbol{P}^{* 1}$ & Intermediate bias corrected precipitation \\
$\boldsymbol{P}_{\boldsymbol{f u t u r e}}$ & Modeled precipitation 2042-2070 \\
$\boldsymbol{P}_{\boldsymbol{o b s}}$ & Observed precipitation 1971-2000 \\
$\boldsymbol{P}_{\boldsymbol{h i n d c a s e}}$ & Modeled precipitation 1971-2000 \\
$\boldsymbol{P}_{\boldsymbol{t h}}$ & Precipitation threshold value \\
$\boldsymbol{S}$ & Scaling factor \\
$\boldsymbol{\sigma}_{\boldsymbol{m}}$ & Long-term monthly standard deviation \\
\hline &
\end{tabular}

\subsubsection{Linear Scaling}

The linear scaling approach (Ines \& Hansen, 2006; Lenderink et al., 2007; Teutschbein \& Seibert, 2012) corrects the RCM-AOGCM model outputs using a ratio of the long-term monthly mean observations to the long-term monthly mean of the model outputs. Because of this, the long-term monthly means of the corrected precipitation will exactly match with the observations. The past and future model outputs were corrected according to the following equations: 


$$
\begin{aligned}
& P_{\text {hindcast }}^{*}=P_{\text {hindcast }} *\left[\frac{\mu_{m}\left(P_{\text {obs }}\right)}{\mu_{m}\left(P_{\text {hindcase }}\right)}\right] \\
& P_{\text {future }}^{*}=P_{\text {future }} *\left[\frac{\mu_{m}\left(P_{\text {obs }}\right)}{\mu_{m}\left(P_{\text {hindcase }}\right)}\right]
\end{aligned}
$$

The long-term monthly mean, $\mu_{\mathrm{m}}$, was calculated as the average of the monthly precipitation over the 30-year model period (29 years for CRCM-CCSM and 28 years for MM5I-CCSM), calculated for each calendar month. The correction factor for the past model outputs was assumed to be stationary and is also applied to the future model outputs.

\subsubsection{Local Intensity Scaling}

The linear scaling bias correction above only corrects biases in the mean (Ines \& Hansen, 2006; Teutschbein \& Seibert, 2012), but the local intensity scaling (LOCI) method corrects for errors in the mean, as well as the wet-day frequency and intensity. The LOCI method (Schmidli et al., 2006; Teutschbein \& Seibert, 2012) first corrects for number of wet days by applying a precipitation threshold to the RCM-AOGCM model output, then corrects the mean based on long-term monthly means of wet days. Because models typically under-predict the number of dry days and over-predict the number of days with low precipitation (Piani et al., 2010), or 'drizzle' days, the precipitation threshold corrects this and assigns a precipitation value of 0 to anything below the threshold. The RCM-AOGCM model's daily precipitation output was corrected according to the following procedure.

(1) A precipitation threshold value for the modeled output was determined so that the number of observed wet days is equal to the number of modeled days that exceed the threshold value. First, the number of observed days with precipitation greater than $0 \mathrm{~mm}(\mathrm{n})$ was calculated. The RCM-AOGCM model's precipitation output was then ordered in descending magnitude and the precipitation value for the $\mathrm{n}^{\text {th }}$ ranked day was selected as the model precipitation threshold, $\mathrm{P}_{\text {th. }}$. The daily RCM-AOGCM model outputs precipitation output was then corrected by reassigning a value of $0 \mathrm{~mm}$ to all modeled days below the threshold.

$$
P_{\text {hindcast }}^{* 1}=\left\{\begin{array}{lr}
0, & \text { if } P_{\text {hindcast }}<P_{\text {th }} \\
P_{\text {hindast }}, & \text { otherwise }
\end{array}\right\}
$$




$$
P_{\text {future }}^{* 1}=\left\{\begin{array}{lr}
0, & \text { if } P_{\text {future }}<P_{\text {th }} \\
P_{\text {future }}, & \text { otherwise }
\end{array}\right\}
$$

In this method, the past RCM-AOGCM model output will have the same wet day frequency as the observed data, but the future RCM-AOGCM model output can have a different wet day frequency from the observed data. It is also important to note that the amount of precipitation from the corrected days was removed and was not redistributed to the remaining days. In this study, one precipitation threshold value for the entire 30 year period was calculated for each model. Calculating a threshold on an annual or seasonal/monthly basis can also be used, but results in a large number of parameters and brings up the issue of over-fitting (Schmidli et al., 2006). For example, threshold values were calculated for all months using the long-term monthly data for the CRCM-CCSM model, resulting in 12 threshold values varying between 0.8853 and $2.7327 \mathrm{~mm}$. When only one threshold value was calculated for the entire 30 year period for the CRCM-CCSM model, the threshold was estimated to be $1.4 \mathrm{~mm}$, which provides a more realistic representation of the long-term precipitation data. Because this study focused on the long-term precipitation trends, the method of calculating one threshold value for the entire "past" period was selected and applied to each model.

(2) The second step in the LOCI method is akin to the linear scaling method, but uses the long-term monthly mean of only wet days. The mean was calculated as the average over the 30 year period of the monthly precipitation in the respective month, only accounting for precipitation that was above $0 \mathrm{~mm}$ for the observed dataset and was above the precipitation threshold for the modeled output. The RCM-AOGCM model output was corrected according to the following equation:

$$
\begin{aligned}
& s=\frac{\mu_{m}\left(P_{\text {obs }} \mid P_{\text {obs }}>0\right)}{\mu_{m}\left(P_{\text {hindcast }} \mid P_{\text {hindcast }}>P_{\text {th }}\right)-P_{\text {th }}} \\
& P_{\text {hindcast }}^{*}=P_{\text {hindcast }}^{* 1} * s \\
& P_{\text {future }}^{*}=P_{\text {future }}^{* 1} * S
\end{aligned}
$$

The scaling factor, $\mathrm{s}$, for this method is the ratio of the wet day intensities of observations to RCM-AOGCM model output adjusted according to the threshold. The future RCM-AOGCM 
model output was corrected using the same scaling factor, therefore forcing the future RCMAOGCM model output to have the same wet day intensity as the observed data.

\subsubsection{Power Transformation}

A non-linear bias correction approach was also tested to correct the variance, which is not accounted for in the linear scaling or local intensity scaling methods (Teutschbein \& Seibert, 2012). The power transformation method (Leander et al., 2008; Leander \& Buishand, 2007; Teutschbein \& Seibert, 2012) corrects the RCM-AOGCM model output so that the exponential form of the RCM-AOGCM model output has the same coefficient of variation (CV) as the observations and is then scaled using a method similar to the linear scaling.

(1) First, the exponential parameter, b, was calculated for each month, using a 3-month window, such that the $\mathrm{CV}$ of the RCM-AOGCM model output raised to the power of $\mathrm{b}$ was equal to the $\mathrm{CV}$ of the observed data, as outlined in the following equation.

$$
C V_{m}\left(P_{\text {hindcast }}^{b_{m}}\right)=C V_{m}\left(P_{\text {obs }}\right)=\frac{\sigma_{m}\left(P_{\text {hindcast }}^{b_{m}}\right)}{\mu_{m}\left(P_{\text {hindcast }}^{b_{m}}\right)}=\frac{\sigma_{m}\left(P_{\text {obs }}\right)}{\mu_{m}\left(P_{\text {obs }}\right)}
$$

The long-term monthly standard deviation and means were calculated using all monthly data in a 3-month window over the 30 year period, resulting in a value for $b$ for each month. For example, the exponential parameter, $b$, for January, was calculated using the monthly precipitation from December, January, and February over all 30 years.

(2) The daily RCM-AOGCM model output was then corrected using the parameter b. The same correction was applied to the RCM-AOGCM model output for future projections.

$$
\begin{aligned}
& P_{\text {hindcast }}^{* 1}=P_{\text {hindcast }}^{b_{m}} \\
& P_{\text {future }}^{* 1}=P_{\text {future }}^{b_{m}}
\end{aligned}
$$

(3) The last step was to apply a linear scaling to the intermediate corrected RCM-AOGCM model output. The RCM-AOGCM model output was multiplied by the ratio of the long-term monthly mean observations to the long-term monthly mean of the intermediate corrected RCMAOGCM model output . 


$$
\begin{aligned}
& P_{\text {hindcast }}^{*}=P_{\text {hindcast }}^{* 1} *\left[\frac{\mu_{m}\left(P_{\text {obs }}\right)}{\mu_{m}\left(P_{\text {hindcast }}^{* 1}\right)}\right] \\
& P_{\text {future }}^{*}=P_{\text {future }}^{* 1} *\left[\frac{\mu_{m}\left(P_{\text {obs }}\right)}{\mu_{m}\left(P_{\text {hindcast }}^{* 1}\right)}\right]
\end{aligned}
$$

The long-term monthly means for the scaling factor were calculated using the same 3-month window used to calculate the exponential parameter, b. The long-term monthly mean was calculated using monthly (adjusted) data from that month, the previous month, and the following month, over all 30 years. In this method, the scaling factor depends on the value of the exponential parameter, $\mathrm{b}$, but $\mathrm{b}$ is not dependent on the scaling parameter.

\subsubsection{Distribution Mapping}

Distribution mapping (DM) (Piani et al., 2010; Teutschbein \& Seibert, 2012), also called probability mapping (Block, Souza Filho, Sun, \& Kwon, 2009; Ines \& Hansen, 2006), corrects the RCM-AOGCM model output by forcing the cumulative distribution function (CDF) of the RCM-AOGCM model output to match the CDF of the observed data. CDFs were created for each month, and the RCM-AOGCM model output was mapped onto the observed data CDF.

To approximate the distribution of both the RCM-AOGCM modeled precipitation outputs and observed precipitation, the Gamma distribution (Thom, 1958) was used ( Eq. (13)), with shape parameter $\alpha$, scale parameter $\beta$, and $\Gamma$ representing the Gamma function. The Gamma distribution is commonly used in analyses of daily precipitation data (Ines \& Hansen, 2006; Katz, 1999; Piani et al., 2010). The shape parameter $\alpha$ determines the specific shape of the distribution. When $\alpha<1$, the probability distribution function (PDF) is exponentially shaped with asymptotes at both the horizontal and vertical axis. When $\alpha=1$, it is a special case where Gamma PDF is the same as the exponential distribution. When $\alpha>1$, the PDF takes on a skewed, mounded shape, with the skewness reducing as $\alpha$ increases. The scale parameter $\beta$ affects the dispersion, or how spread out the distribution is. If $\beta$ is larger, then the distribution is less compressed, meaning that larger precipitation events have a higher probability of occurring.

$$
f_{\gamma}(x \mid \alpha, \beta)=\frac{x^{\alpha-1}}{\beta^{\alpha} \Gamma(\alpha)} * e^{-\frac{x}{\beta}} ; x \geq 0 ; \alpha, \beta>0
$$

To apply the distribution mapping approach, the following procedure was used. For both the observed data and RCM-AOGCM model output, a Gamma CDF was created for each month, 
using all the daily data in the respective month over the 30 year period. Because the models often predict too many days with very low precipitation, the threshold value from the LOCI bias correction method (Eq. (3) and Eq. (4)) was applied to the RCM-AOGCM model output before the CDFs were constructed. To correct the RCM-AOGCM model output, the probability was read from the modeled CDF for each precipitation value in the respective month. The corrected precipitation value was then read from the observed CDF using that same probability. It can also be expressed mathematically with the following expression, where $F_{\gamma}$ is the Gamma $\mathrm{CDF}, F_{\gamma}^{-1}$ is the inverse $\mathrm{CDF}, \mathrm{P}$ is the daily precipitation, and $\alpha$ and $\beta$ are the monthly Gamma distribution parameters.

$$
\begin{aligned}
& P_{\text {hindcast }}^{*}=F_{\gamma}^{-1}\left(F_{\gamma}\left(P_{\text {hindcast }} \mid \alpha_{\text {hindcast }}, \beta_{\text {hindcast }}\right) \mid \alpha_{o b s}, \beta_{\text {obs }}\right) \\
& P_{\text {future }}^{*}=F_{\gamma}^{-1}\left(F_{\gamma}\left(P_{\text {future }} \mid \alpha_{\text {hindcast }}, \beta_{\text {hindcast }}\right) \mid \alpha_{o b s}, \beta_{\text {obs }}\right)
\end{aligned}
$$

Again, the correction was also assumed to be valid for the future conditions, so the future RCMAOGCM model output was corrected using the CDF parameters calculated from the past RCMAOGCM model output.

\subsubsection{Performance Metrics}

In order to evaluate the performance of the climate models and bias corrected RCM-AOGCM model output, several performance metrics were used. All of the modeled and bias corrected outputs were compared against the observed data for the past time period. Bias correction methods cannot be validated for the future data, only for the past dataset. Validating the past data will not prove that the future data will accurately reflect future conditions, but by showing that a bias correction method applied to the past data accurately simulates the observed data, we can assume that the same bias correction method applied to the future data is more likely to match actual conditions than a bias correction method that performs poorly during the past period (Teutschbein \& Seibert, 2012).

Each bias correction method was applied to and evaluated for each model on an individual basis. The best performing bias correction methods for each model were selected and applied to the future RCM-AOGCM model output to create an ensemble of bias corrected outputs for input into the hydrological model. The performance metrics used to evaluate the bias correction methods and raw model outputs, similar to those used by Rupp et al. (2013), were the long-term monthly 
mean, seasonal amplitude, annual precipitation, long-term monthly coefficient of variation, and annual coefficient of variation. These error metrics cover a variety of properties, including mean and variance on both monthly/seasonal and annual scales. A normalized error value (Eq. (16)) was calculated for each error metric to provide a means of comparing errors across metrics and time scales (Rupp et al., 2013). A normalized error value of 0 means that the modeled or bias corrected outputs exactly match the observations. The farther the error is away from 0 , the worse the performance of the data. A positive error value means that the data being evaluated are overpredicting the observations and a negative value corresponds to an under-prediction of the observations.

$$
\text { Normalized Error }=\frac{\text { Model value }- \text { Observed value }}{\text { Observed value }}
$$

\subsubsection{Long-term Monthly Mean}

The long-term monthly mean was calculated as the average of all monthly data over the 30 year period for each month. The long-term monthly means were calculated for each climate model and each bias correction method. The normalized error was calculated for each month and then averaged for each season to measure the average seasonal trends.

\subsubsection{Seasonal Amplitude}

The seasonal amplitude was calculated as the difference between the wettest and driest month in each year. The seasonal amplitude was calculated for each year individually for the model and bias corrections. Those annual values were also averaged over the entire 30 year period to give an overall average estimate. The normalized error was calculated using the overall average seasonal amplitude.

\subsubsection{Annual Precipitation}

The annual precipiation error metric is the sum of all precipitation during each year. Again, to calculate the normalized error, the average of all the annual precipitations over the 30 year period was used.

\subsubsection{Long-term Monthly Coefficient of Variation}

The long-term monthly coefficient of variation was computed for each month of the year as the

coefficient of variation (standard devitation over the mean) using monthly data for the respective 
months, over the 30 year period. Similarly to the long-term monthly mean, the normalized error was calculated for each month and then averaged for each season.

\subsubsection{Overall Annual Coefficient of Variation}

The annual coefficient of variation was calculated as the overall coefficient of variation, using all the annual precipitation data over the 30 year model period. The normalized error value was calculated using the computed single coefficient of variation value.

\subsubsection{Ensemble Selection}

Each of the four bias correction methods was applied to all 8 NARCCAP climate models to develop 32 realizations of bias corrected RCM-AOGCM model output in addition to the 8 raw (i.e., uncorrected model outputs) datasets. Each realization (raw and bias corrections) was evaluated using the above performance metrics. For each performance metric, the model realization was given a normalized error value so that the errors could be compared across metrics and time scales, as discussed in an earlier section. Then for each realization, the absolute value of the normalized error was summed up across the performance metrics to provide an overall error for the model realization.

The total error for each climate realization dataset was compared to determine which realizations best represented the observed watershed climate and which realizations should be removed from the ensemble. Realizations were removed from the ensemble if their error was closer to the worst raw model error than the best bias-corrected realization error.

\subsection{Hydrologic Model Calibration and Evaluation}

The SWAT model was used to simulate the streamflow for the Eagle Creek Watershed. Similar to the method used by Grillakis et al. (2011), the model was calibrated and evaluated separately for the observed climate data by comparing with observed streamflow. The model was calibrated for the "current" time period of 2001-2012 and evaluated for the "past" period of 1971-2000. The years 2000 and 1970, for their respective time period, were discarded as "model spin-up" years. Calibration was performed by comparing the streamflow at the outlet of sub-basin 70 in the SWAT model, using historic observed climate data for the NOAA station at Whitestown, IN (station ID GHCND: USC00129557), to observed flow from the USGS station at Zionsville, IN. 
When comparing the baseline past scenarios (simulated using the climate model "past" output from 1971-2000) to the future scenarios (simulated using the climate model "future" output from 2041-2070), moderate calibration of the SWAT model for the site is generally sufficient (Gosain et al., 2006). A simple calibration based on physical values and calibrated values found by Piemonti et al. (2013) was performed on the SWAT model. The Muskingum routing method was selected for channel routing. Several tile drain parameters were also modified as listed in Table 3 , based on typical values found for tile drains in central Indiana. To help the model capture the decreasing streamflow trend after small peaks, some calibration was performed on infiltration and interflow parameters. The groundwater parameters and curve numbers (values based on calibration done by Babbar-Sebens et al., 2013) shown in Table 4 were adjusted to calibrate the model.

Table 3. Tile drain parameters for central Indiana used to calibrate the SWAT model

\begin{tabular}{ll}
\hline PARAMETER & VALUE \\
\hline DED_IMP (depth to impermeable layer) & $2500 \mathrm{~mm}$ \\
DDRAIN (depth to tile drains) & $1000 \mathrm{~mm}$ \\
TDRAIN (time to drain soil to field & $24 \mathrm{hr}$. \\
capacity) (tile drain lag time) & $96 \mathrm{hr}$. \\
GDRAIN & \\
\hline
\end{tabular}

Table 4. Calibration parameters and initial (i.e., default) and calibrated values

\begin{tabular}{|c|c|c|}
\hline PARAMETER & $\begin{array}{l}\text { INITIAL } \\
\text { VALUE }\end{array}$ & $\begin{array}{l}\text { CALIBRATED } \\
\text { VALUE }\end{array}$ \\
\hline $\begin{array}{l}\text { CN_FROZ (FROZEN GROUND CURVE } \\
\text { NUMBER) }\end{array}$ & 0.00862 & 1 \\
\hline $\begin{array}{l}\text { GW_DELAY } \\
\text { DELAY TIME) }\end{array}$ & 31 days & 0 days \\
\hline $\begin{array}{l}\text { GWQMN (Threshold of water in shallow } \\
\text { aquifer required for return flow to occur) }\end{array}$ & $1000 \mathrm{~mm}$ & $0 \mathrm{~mm}$ \\
\hline $\begin{array}{l}\text { RCHRG_DP (Deep aquifer percolation } \\
\text { fraction) }\end{array}$ & .05 & 0.0001 \\
\hline $\begin{array}{l}\text { CN2 (Initial SCS runoff curve number for } \\
\text { moisture condition II) }\end{array}$ & $\begin{array}{l}\text { Specific to land } \\
\text { use }\end{array}$ & $\begin{array}{l}\text { CORN, SOYB } \\
0.8075^{*} \mathrm{CN} 2_{\text {default }} \\
\text { HAY: } \\
\text { CN2 } 2 \text { default } \\
\text { All Other Land Use: } \\
0.95^{*} \mathrm{CN} 2_{\text {default }}\end{array}$ \\
\hline
\end{tabular}


The model error for calibration and validation was computed for both daily and monthly streamflow values using the Nash-Sutcliffe efficiency (NSE) (Nash \& Sutcliffe, 1970), as given by Eq. (17) and the square of Pearson's product moment correlation coefficient $\left(\mathrm{R}^{2}\right)$. The NSE calculates how well a plot of observed data and simulated data fit a 1:1 line. NSE was selected because it has found to be the best metric for evaluating overall fit of a hydrograph (Servat \& Dezetter, 1991). NSE varies from $-\infty$ to 1 and an NSE equal to 1 denotes perfect model performance. Values less than 0 mean that the average of the observations is a better predictor than the model.

$$
N S E=1-\frac{\sum_{i=1}^{n}\left(O_{i}-M_{i}\right)^{2}}{\sum_{i=1}^{n}\left(o_{i}-O_{\text {avg }}\right)^{2}}
$$

where $O$ is the observed flow value, $M$ is the modeled flow value, and $n$ are the number of data points used for calibration or evaluation.

\subsection{Streamflow Analysis}

Using the calibrated SWAT model, all of the "past" climate output realizations were run individually through the model. The resulting streamflows were compared as another metric to evaluate the performance of the climate models and their ability to represent the watershed. The uncertainty due to the assumptions in the underlying SWAT model was addressed during the calibration and validation of the model. So to separately evaluate the effect of the RCMAOGCM model climate output on uncertainty in model predictions, the resulting streamflows using each of the climate model outputs were compared to the streamflow output of the model run with observed climate data. Because this study is interested in the long-term seasonal effects of climate change on wetland impacts, the long-term monthly mean was used to evaluate the modeled streamflows for each climate realization. The long-term monthly mean was calculated as the average of all monthly data over the 1971-2000 time period in the respective month.

To further narrow down the ensemble of climate realizations and eliminate climate realizations that do not produce streamflow trends representative of the area, a standard error boundary was calculated. The standard error (SE) of the long-term monthly mean stream flow using observed 
climate was computed for each month using the formula in Eq.(18), where $S E$ is the standard error, $s$ is the sample standard deviation, and $n$ is the number of data points.

$$
S E=\frac{S}{\sqrt{n}}
$$

The error boundary was set at \pm 3 times the standard error to approximate a $99 \%$ confidence interval. Any climate realization run that had more than $10 \%$ of the data outside of the error bounds were then removed from the final ensemble.

To further evaluate the final ensemble of climate models, long-term monthly Gamma cumulative distribution functions (CDFs) were fitted to each realization and compared to the CDF of the modeled streamflow using observed climate data. All of the daily data from the respective month was used to fit the CDF. A Gamma distribution was approximated for each month and fit to the data with the shape and scale parameters, $\alpha$ and $\beta$, respectively.

\subsection{Land Use Analysis}

In the Eagle Creek Watershed and surrounding areas, it is projected that urban development will continue to grow and could affect future hydrological components. In order to investigate the effect that land use change, specifically urban growth, would have on streamflow, the results from two cases were compared for each climate model realization: a future run with constant land use from 2012 and a future run with projected urban growth land use. Each of the future climate projections from the final ensemble of realizations was run through the hydrologic model using the 2012 land use and again using a projected land use map.

The projected land use map was created by combining the 2012 land use map from the USDA with future urban growth predictions for 2050 from the National Land Transformation Model by Purdue University (National Land Transformation Model, 2013). The projected urban areas from the 2050 land use map were overlaid on top of the 2012 land use map to form the new land use projection map. The land use projection map therefore has the same land use as the 2012 map for all land use types except for the urban areas. Figure 4 shows the 2012 land use map (left) and the projected land use map (right), where the growth of urban areas (shown in purple) can be seen. 

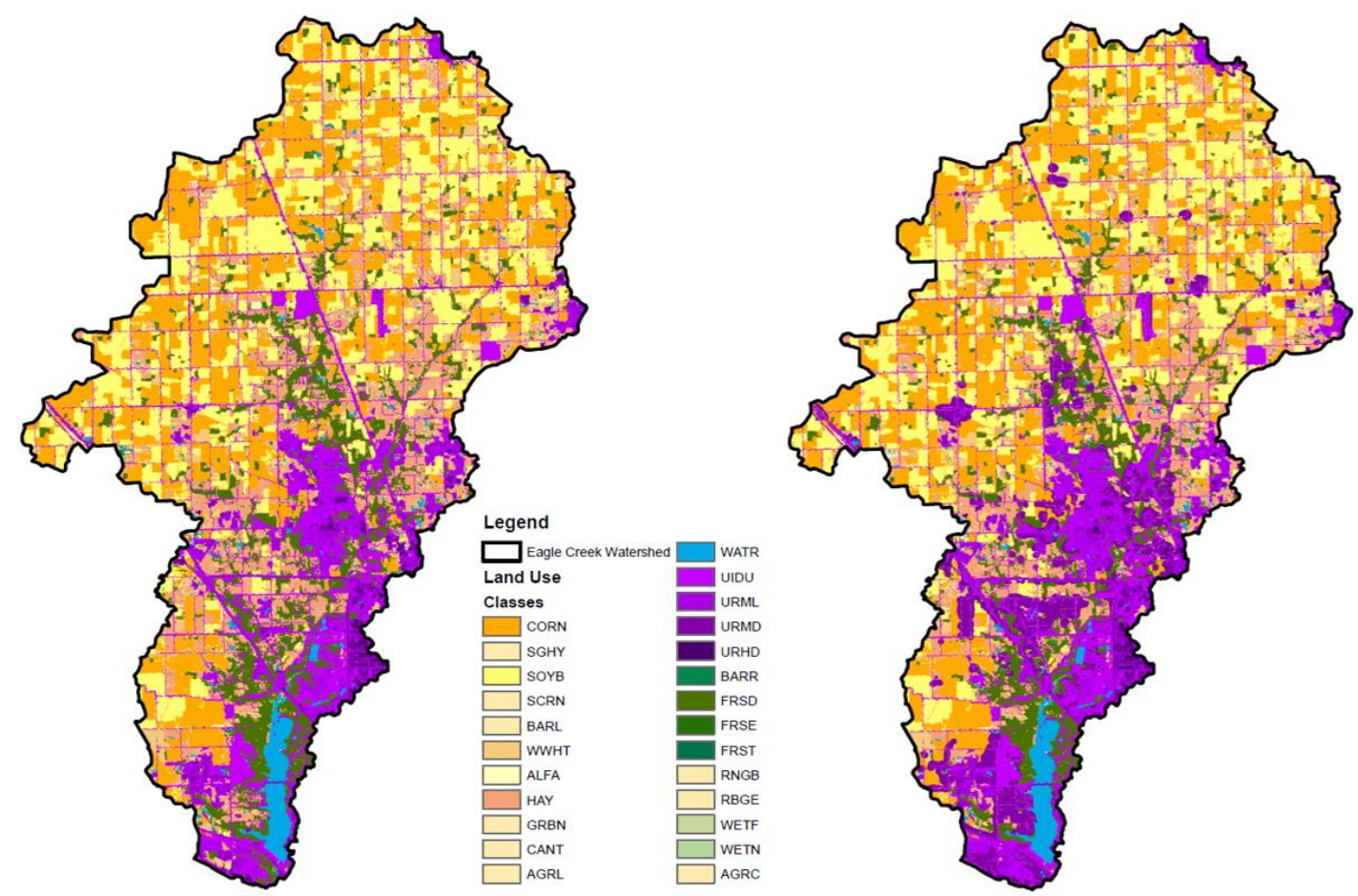

Figure 4. Land use maps used for land use change comparison. Land use from 2012 (left) and land use with projected urban growth for 2050 (right). UIDU, URML, URMD, and URHD signify urban areas.

The streamflows resulting from the model runs with the projected land use were compared to streamflows from the model runs with the 2012 land use to see the effect of land use change. The flow was compared on a daily basis and the maximum difference was calculated.

\subsection{Climate Change Analysis}

The climate change from the past (1971-2000) period to the future (2041-2070) period was assessed with a streamflow analysis and an extreme event analysis. To compare the streamflow from the past to the future, the long-term monthly streamflow was computed as the average monthly streamflow (from sub-basin 70) over the model period for the respective month, as calculated for the past period in section 3.3. The long-term monthly mean streamflow shows the change in overall seasonal flow trends due to the projected climate change.

An extreme event analysis was performed on high flows to evaluate the expected changes from current to projected trends. The extreme event analysis compared the streamflow output from the calibrated hydrological model at sub-basins 70 and 110 for the 1971-2000 period to the 20412070 period for each climate realization in the final ensemble. The high flow events were 
analyzed by calculating the daily Q05 value, or the daily streamflow with a 5\% exceedance, for each 30-year period. Similarly to Whitfield et al. (2003), the historic Q05 value was determined, and then compared to the projected future streamflow to find the frequency of events with the same magnitude. The Q05 value was also calculated for the future projected streamflows and compared against the past Q05 values. In addition to analyzing the changes in flood frequency, the seasonal distribution of floods was also examined. To find the seasonal distribution, the percent of flood events, defined as days with streamflow equal to or greater than the Q05 value, occurring in each month of the year were calculated by counting the number of flood event days occurring in the month divided by the total number of flood event days over the 30-year period. The percent of flood event days occurring in each month in the past were then compared to the percent occurring in the future to identify any seasonal shifts.

\subsection{Wetland Analysis}

To analyze the benefits gained from installing and restoring wetlands, both an extreme event analysis and peak flow reduction analysis were performed. Using a GIS-based suitability analysis technique, Babbar-Sebens et al. (2013) had identified 2,953 potential wetlands, located in 108 of the 130 total sub-basins in the watershed. The technique uses spatial data layers on land use type, soil drainage characteristics, and a compound topographic index derived from the digital elevation model to assess suitable sites where wetlands could be created. In this study, we used all of the potential wetland locations identified by Babbar-Sebens et al. (2013) as sites with restored wetlands to assess the maximum impact from all the potential wetland sites on the watershed. All of the wetlands were added to the calibrated SWAT model (similar to approach used by Babbar-Sebens et al. (2013)) and the model was run for both the past and future time periods. The past time period without wetlands was compared to the past time period with wetlands to see possible benefits that could have been gained if the wetlands had been installed in the past. These simulated past benefits were used as a baseline of benefits to compare with the future benefits predicted using the climate-change scenario. The future period without wetlands was then compared to the future period with wetlands to estimate the impact of restoring or not restoring wetlands in the projected future scenarios. The same extreme event analysis performed for the past to future scenarios comparison was also performed for the "no wetlands" to "wetlands" cases, for both past and future time periods. The Q05 value was calculated for both 
cases and compared to assess flood mitigation capacity of wetlands. The seasonal distribution of Q05 and greater streamflow events was also then calculated for the future time period.

In addition to the Q05 streamflow analysis, a peak flow reduction analysis was conducted for the wetland cases. Using the daily data, the difference in peak flows, or peak flow reduction (PFR), between the "no wetlands" and "wetlands" cases were calculated for each sub-basin containing wetlands. Across all the sub-basins and 30 years, the maximum reduction in peak flow was calculated for each climate realization, according to Eq. (19).

$$
\begin{gathered}
\operatorname{PFR}_{\max , k}=\max _{i, n, k}\left(\text { peakflow }_{i, n, k, \text { baseline }}\right. \\
\left.-\operatorname{peakflow}_{i, n, k, \text { wetlands }}\right)
\end{gathered}
$$

Where $P F R_{\text {max }}$ is the overall maximum peak flow reduction, $i$ is the sub-basin, $n$ is the day, $k$ is the climate realization, baseline is the "no wetlands" case, and wetlands is the "wetlands" case.

The robustness of wetlands as a solution for peak flow reduction was evaluated by looking at the average reduction for streamflows within a given range. The daily streamflows output from each climate model was divided into ranges from $0-50 \mathrm{~m}^{3} / \mathrm{s}, 50-100 \mathrm{~m}^{3} / \mathrm{s}, 100-150 \mathrm{~m}^{3} / \mathrm{s}$, and $150 \mathrm{~m}^{3} / \mathrm{s}$ and above. The average reduction in streamflows by "wetlands" was computed for each climate model and for each streamflow range. To examine robustness, the average across the climate models, the standard deviation, and the coefficient of variation were calculated. Lower standard deviations means that all of the models closely agree in the average predicted peak flow reduction, meaning that no matter which climate projection were to occur, a similar peak flow reduction result is expected. The coefficient of variation is also a good measure of robustness, incorporating the average reduction and the standard deviation. A lower coefficient of variation is a more robust solution because it has a lower standard deviation across climate realizations and a higher average flow reduction.

To further analyze the peak streamflow reduction benefits due to the wetlands, for the sub-basin that contained the maximum peak flow reduction, a distribution was fit to the daily peak flows above a threshold to determine any changes in frequency of high flow events for the future time period. The Q05 daily streamflow value of the "no wetlands" case was computed as the threshold 
to analyze only peak flows with magnitudes in the top 5\% of streamflow values. All peak flows equal to or greater than the Q05 threshold value were fit with a Gamma distribution. The distributions of the high peak flows for the "no wetlands" and "wetlands" cases were then compared to see the shift in probability of occurrence of these events. To compare the two distributions, the difference in the median value, or streamflow with a probability equal to 0.5 , was computed. This was then used as an expected change in magnitude of the streamflow event that is likely to be exceeded half of the time by peak flows above the Q05 value when wetlands are installed.

\section{RESULTS AND DISCUSSION}

\subsection{Climate Data Analyses}

To evaluate how well the raw regional climate model outputs capture the long-term seasonal trends, the long-term monthly mean was calculated for the maximum temperature, minimum temperature and the precipitation. Both the maximum and minimum temperatures were well simulated by the NARCCAP models (Figure 5Figure ). Square of the Pearson product moment correlation coefficient, or $\mathrm{R}^{2}$, for the maximum temperature ranged from 0.97 to 0.99 and for minimum temperatures ranged from 0.96 to 0.99 , indicating very high correlation with the observed values. The monthly observed trend in temperatures was closely followed by each NARCCAP model, giving us confidence that the climate models are a good representation of temperature in the watershed.

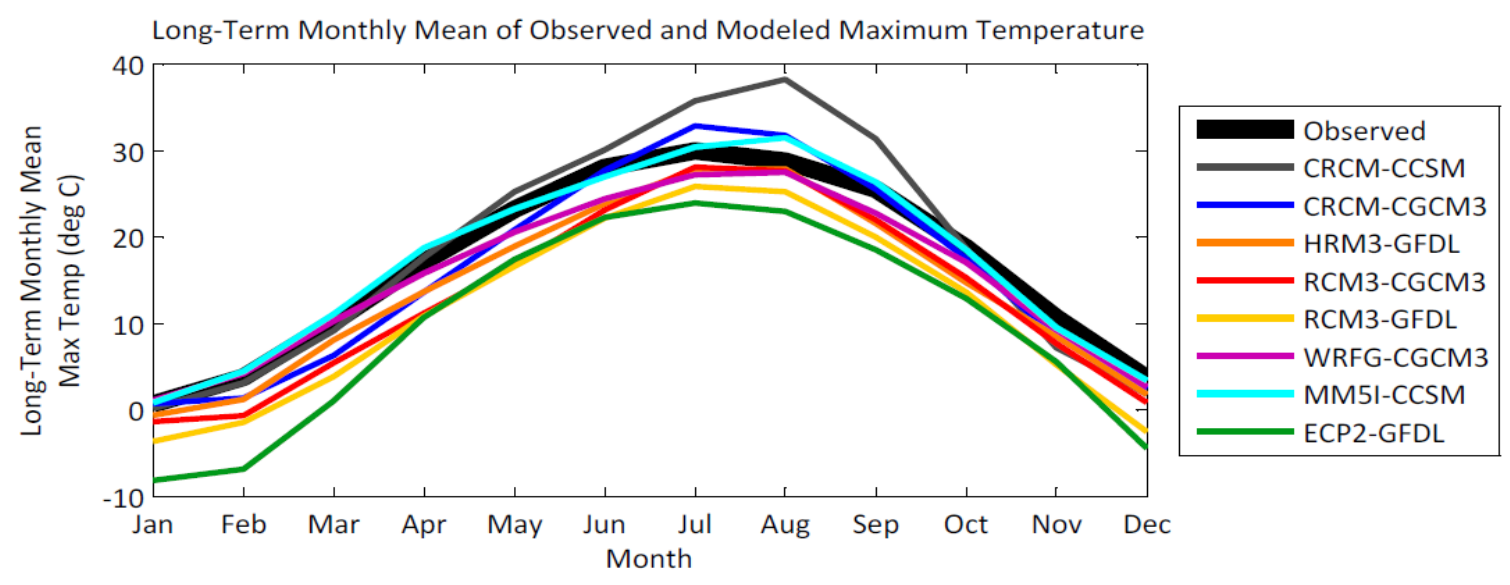




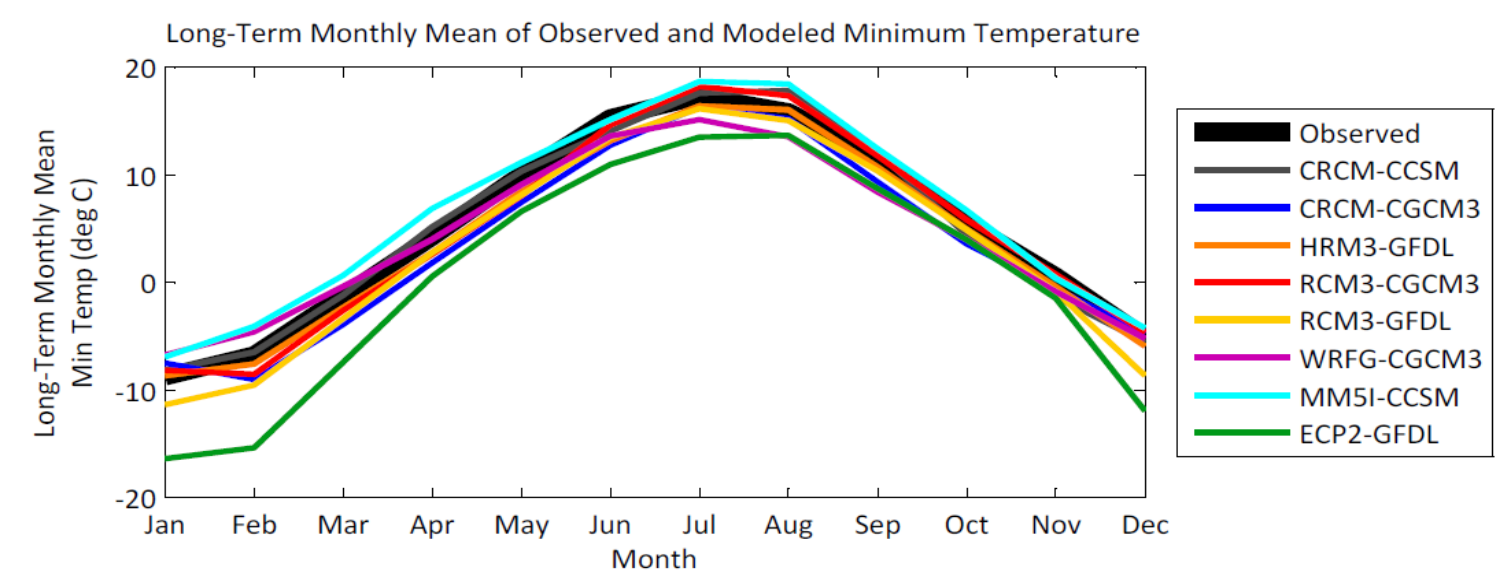

Figure 5. Long-term monthly mean of observed and modeled maximum (top) and minimum (bottom) temperatures for the past (1971-2000) period.

The observed precipitation, however, was not simulated as well by the NARCCAP models (Figure 6). Climate models tend to have difficulty in producing accurate precipitation predictions, especially extreme events, which can lead to inaccurate hydrological modeling results (Ines \& Hansen, 2006; Teutschbein \& Seibert, 2010, 2012). For precipitation, $\mathrm{R}^{2}$ ranged from .003 to 0.86 . This shows that most of the models have very poor correlation to the observed data. In Figure 6, it can be seen that some of the models follow the overall seasonal trend of observed precipitation, but many have more extreme values and differ in the timing of peaks and troughs. Most of the models tend to over-predict the observations in the spring (April-June), while some models under-predict in the summer and fall (July-November), and are split in overand under-predictions in December-February. 


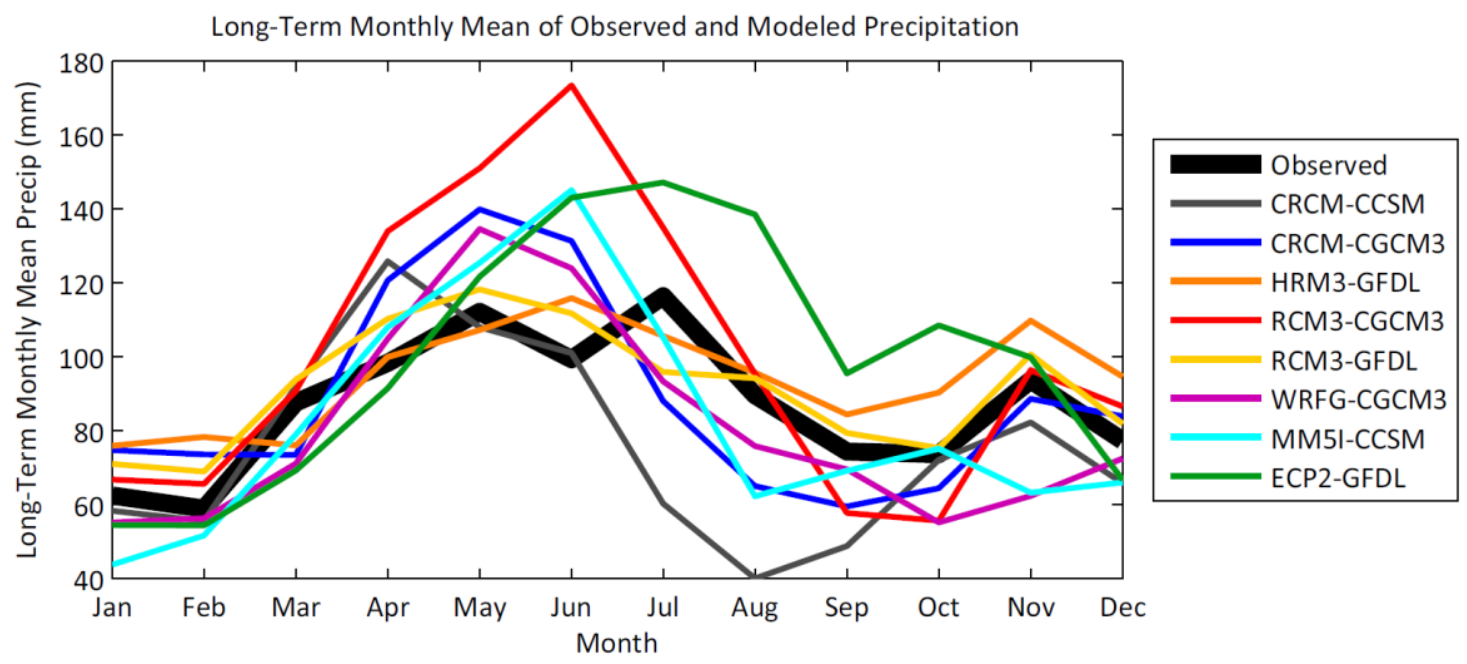

Figure 6. Long-term monthly mean of observed and modeled precipitation for the past (1971-2000) period.

In addition to the long-term monthly mean, the seasonal amplitude was also computed for the raw models, as the difference between the wettest and driest month each year. Figure 7 shows the observed and modeled seasonal amplitudes for the past (1971-2000) period. None of the models accurately follow the observed seasonal amplitude trends. $\mathrm{R}^{2}$ for the seasonal amplitude range from 0.004 to 0.2 , showing a very poor agreement with the observed data.

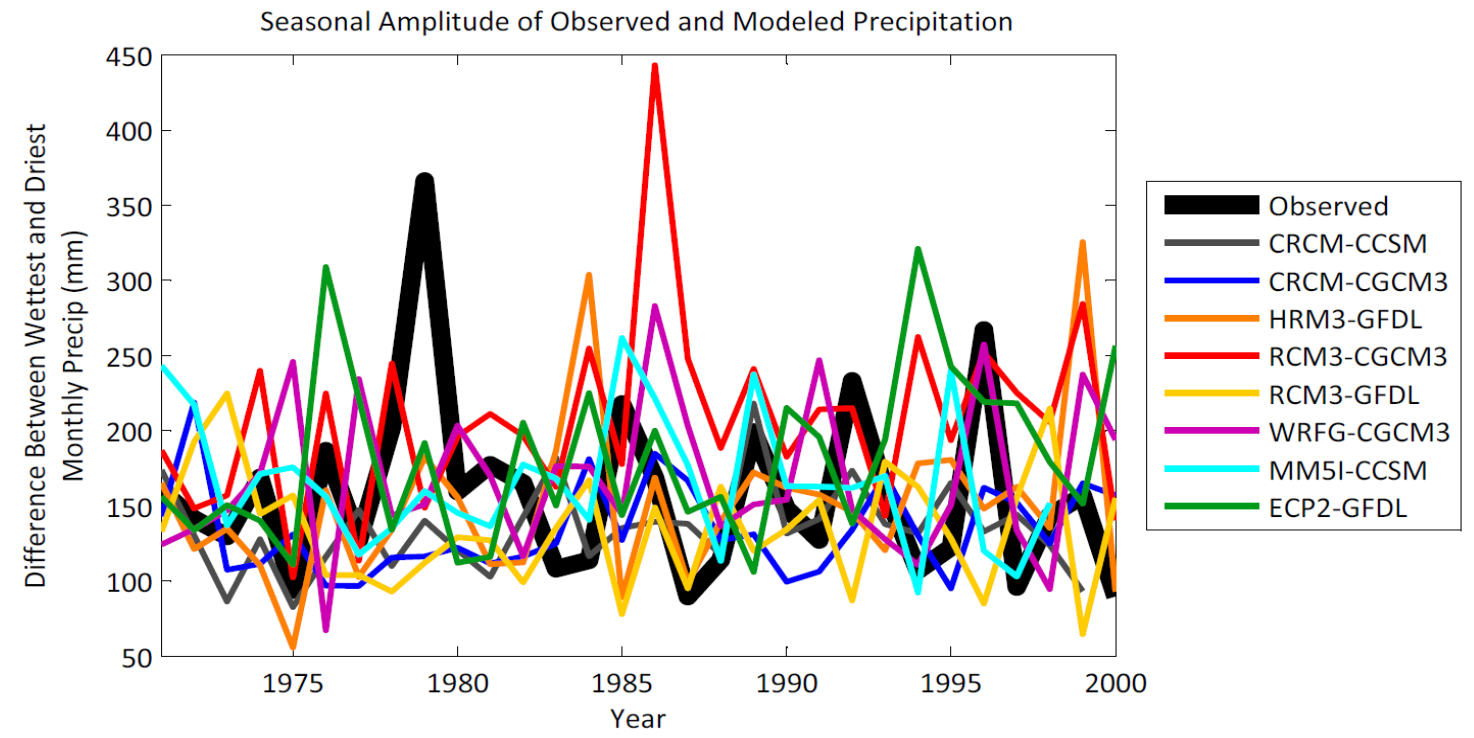

Figure 7. Seasonal amplitude of observed and raw model precipitation for the past (19712000) period. 
Similarly, total annual precipitation was also calculated for each model and compared to the observed precipitation. Some models, although shifted in years, predict similar ranges of annual precipitation, but others tend to over-predict the annual precipitation. $\mathrm{R}^{2}$ for the annual precipitation ranged from 0.0004 to 0.1 , demonstrating even worse agreement with observed precipitation. Finally, the long-term coefficient of variation was calculated for each month. $\mathrm{R}^{2}$ for the long-term monthly coefficient of variation ranged from 0.06 to 0.49 . The under-prediction of the coefficient of variation means that the models are not accurately capturing the variation seen in the observed precipitation data.

The inability of the climate models to accurately simulate the observed precipitation led to the need for bias corrections on the RCM-AOGCM model climate output precipitation. A study done by Jha et al. (2006) found that precipitation and $\mathrm{CO}_{2}$ fertilization shifts had the greatest impact on future flow changes compared to the impacts seen from increased temperatures. Though Jha et al. (2006) did not use bias correction methods, but recommended more extensive studies with downscaled climate data and a need for improvement to the modeled precipitation output.

\subsubsection{Bias Correction}

\subsubsection{Linear Scaling}

The annual cycle of scaling factors for the linear scaling bias correction method, calculated as the ratio of long-term monthly mean observations to the long-term monthly mean of the RCMAOGCM model climate output, ranged from 0.57 to 2.24 across all RCM-AOGCM models. A scaling factor of greater than one indicates that the model is under-predicting the observations. More than $50 \%$ of the models over-predicted the precipitation in the winter and spring months (January-June), and more than $60 \%$ of the models under-predicted the precipitation in the summer and fall months (July-December).

\subsubsection{Local Intensity Scaling}

The threshold values used in the local intensity scaling bias correction method for each model ranged from 0.503 to as high as $1.704 \mathrm{~mm}$. The lower threshold values show that those models are more closely simulating the rainfall frequency in the long term, but still tend to predict more days with low intensity rainfall. This is consistent with previous studies that have found climate models produce too many drizzle days (Ines \& Hansen, 2006; Piani et al., 2010; Teutschbein \& 
Seibert, 2010). The scaling factors, s, for the local intensity scaling bias correction were also calculated for each month. The scaling factors (ranging from 0.59 to 2.72) were found to be similar to those in the linear scaling bias correction approach, but a little more spread out, again showing a variety of over- and under-predictions in the ensemble. Many of the models have a scaling factor below 1, corresponding to the models over-predicting the observations in the spring (April-June), and above 1, or under-predicting, in the summer, fall, and winter (JulyMarch). Despite these trends, at least one model was found to over-predict and at least one under-predict precipitation each month, demonstrating that the ensemble of models capture a wide range of predictions.

\subsubsection{Power Transformation}

The power transformation (PT) bias correction applies a monthly exponential parameter, $b$, to the RCM-AOGCM model climate output, calculated such that the coefficient of variation of the observed data is equal to that of the RCM-AOGCM model climate outputadjusted with exponential parameter. The resulting values for the exponential parameter, were generally greater than one for $76 \%$ of the values, showing that, on average, the raw models were underestimating the $\mathrm{CV}$ of the observations. Underestimating the $\mathrm{CV}$ of the observations means that the models are not adequately capturing the variance, or dispersion, of the observations. Hence, the PT bias correction was attempted to correct the models so that they more accurately reflect the variance in the observations. The long-term monthly scaling factors for the PT bias correction of all models were found to range from 0.10 to 1.68. The bias-corrected RCMAOGCM model climate output now generally over-predicted the long-term monthly averages of the observations, with factors of less than one for most of the models year-round. The dependency (inverse relationship) of the scaling factor on the exponential parameter, $b$, was seen in the summer months, where the higher $b$ value resulted in a lower scale factor.

\subsubsection{Distribution Mapping}

Gamma distributions were fit to the observed data for each month for use in the distribution mapping (DM) bias correction. The observed CDFs were found to have an $\alpha$ value ranging from 0.72 (in November) to 1.018 (in May), showing that most months follow an exponentially shaped PDF. The distribution for May is the special case that matches the exponential distribution. The value of $\beta$ for the observed data ranges from 6.784 (in January) to 15.591 (in 
July), showing a large range of compressed and stretched distributions. The CDFs for the summer months were found to be more stretched out, or have a less sharp curve, meaning that larger storm events are more likely to occur, which is consistent with the higher average precipitation trends seen in the late spring/summer in the watershed. This also corresponds to the larger $\beta$ values in the summer.

The CDFs of the RCM-AOGCM model climate output precipitation were also constructed using the raw RCM-AOGCM model climate output after the precipitation threshold (from the LOCI bias correction method) was applied. The resulting $\alpha$ and $\beta$ values showed no clear trend and many models did not follow the pattern of the fitted parameters in the CDFs of the observed data. For the ensemble of models in general, both the $\alpha$ and $\beta$ values show better agreement with the observed parameters in October through May, and very poor agreement in the summer (JuneSeptember). The observed $\alpha$ values stay relatively constant throughout the year, fluctuating between 0.7 and 1 , while the modeled $\alpha$ values fluctuated greatly between about 0.7 and 3.25. This created a variety of PDF (probability density function) shapes, including some exponentially shaped and others with a more mounded, skewed shape, correlating to CDFs that are both logistic and logarithmic shaped. In general, the modeled $\alpha$ values were higher than the observed values for all months. A higher $\alpha$ value means that the modeled CDFs are more stretched out and larger storm events have more likelihood of occurrence. The modeled $\beta$ values also varied extensively, from 1.2 to 12 , showing both compressed and stretched distributions. The models tended to have more compressed distributions than the observed distribution, as demonstrated by the minimum $\beta$ value for the observed data being 6.784 and for the RCMAOGCM model climate output being 1.2. These large errors in the $\alpha$ and $\beta$ values show that the raw models have limited capability in predicting the distribution of precipitation for this area, and again confirms the need for bias correction.

Before the bias correction was applied, the modeled CDFs took on a much tighter s-curve shape than the more logarithmic shaped observation CDFs did, especially for the summer months (May-September), as seen in the example for the CRCM-CCSM model (Figure 8). This shows that the models are predicting higher probability of low-precipitation days, especially in the months with higher mean precipitation. This is consistent with other findings that models typically produce too many 'drizzle' days (Ines \& Hansen, 2006; Piani et al., 2010; Teutschbein 
\& Seibert, 2010). After the distribution mapping correction was applied to the modeled output precipitation, a new Gamma CDF was fitted to the corrected output to confirm that the new precipitation values would have the same distribution as the observed data.
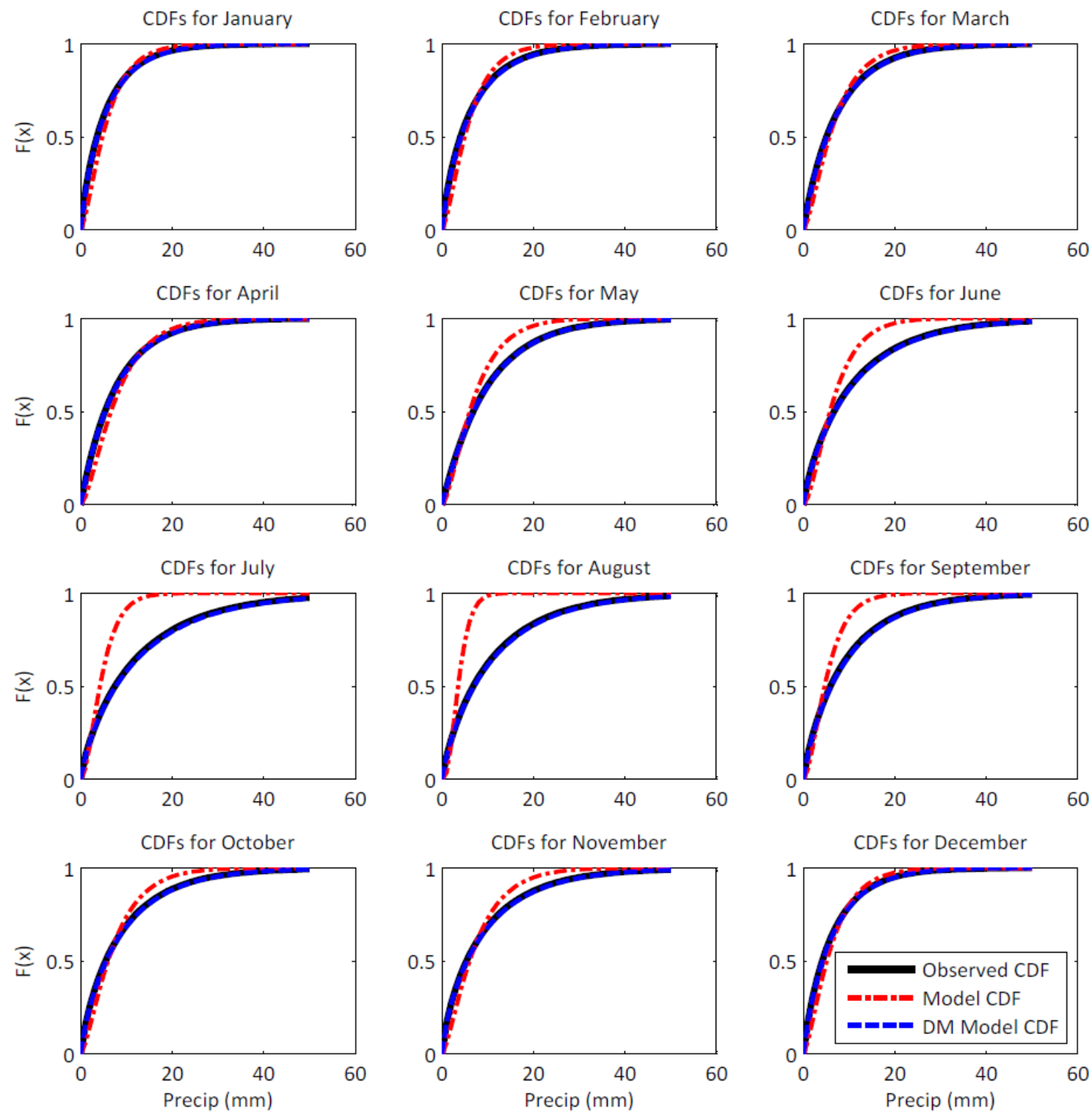

Figure 8. Long-term monthly Gamma CDFs fitted to the observed data(black), raw model output (red), and DM corrected model output (blue) for CRCM-CCSM model. DM corrected model output and observed data share the same CDF.

After the bias correction, the modeled $\alpha$ and $\beta$ values very closely agree with the observed values, resulting in matching CDFs (as seen in the example in Figure ) and correction in the over-prediction of low-precipitation days and under-prediction of high-precipitation events. 


\subsubsection{Performance Metrics}

\subsubsection{Long-term Monthly Mean}

The long-term monthly mean precipitation was calculated from the monthly data over the 30year model period. The results for the CRCM-CCSM model are shown as an example in Figure 9.

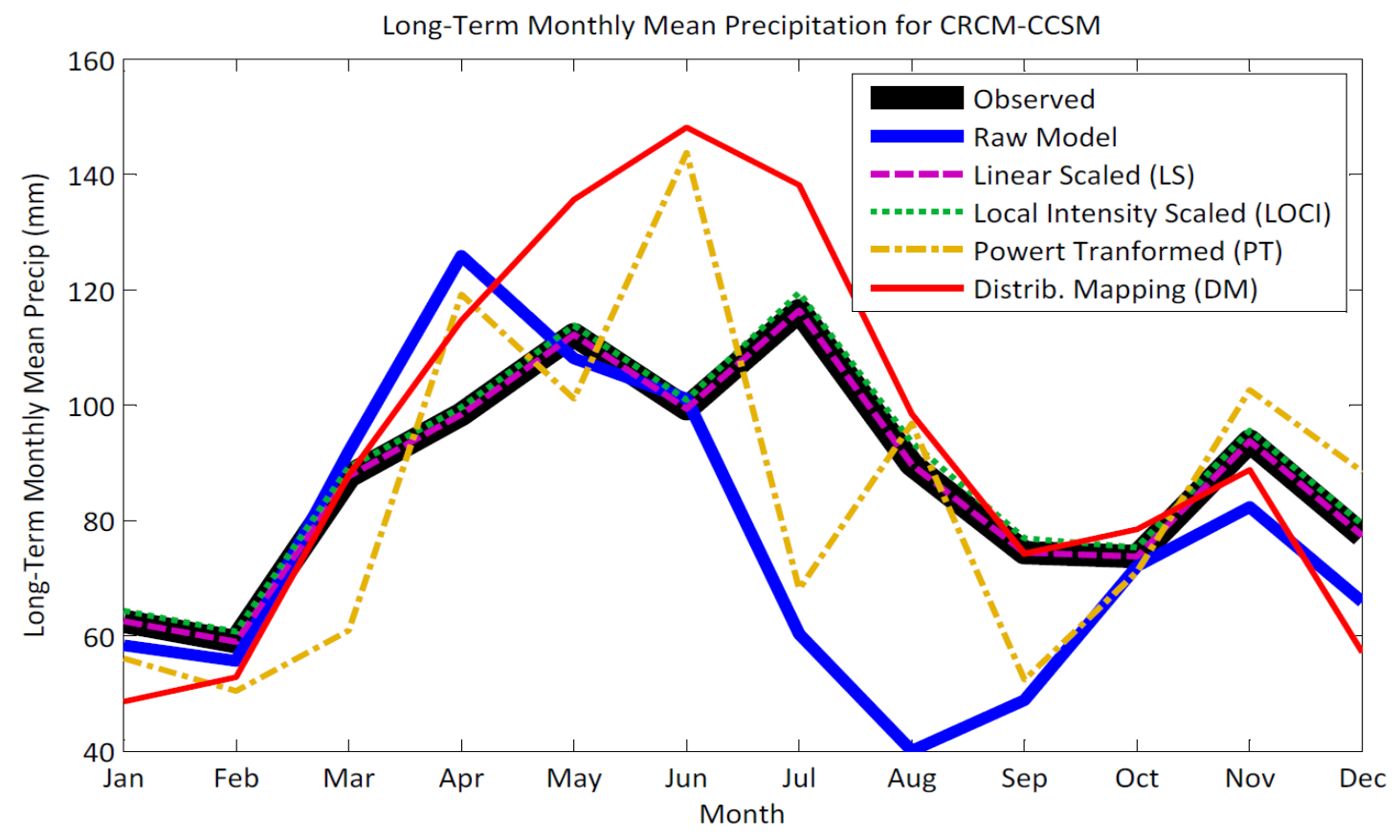

Figure 9. Long-term monthly mean precipitation for 1971-1999 for the CRCM-CCSM model.

As seen in the example for the CRCM-CCSM model (Figure 9), the linear scaling and LOCI methods showed very good agreement with the long-term monthly means of the observed data due to using those values in the calculations. Because of the methods used in both of those bias corrections, the same trend was seen across all of the models: the LS approach exactly matched the observed long-term monthly means and the LOCI approach had very low errors. The power transformation method, however, did not capture the observed trends as well and was much more varied in the means, both over- and under-predicting, depending on the month. This trend seen for the CRCM-CCSM model example (Figure 9) is similar across all the models. Some models showed slightly higher or lower fluctuations and most models had a higher peak (overpredictions) in June. For almost all the models, the distribution mapping method matched the 
general trend of the observed data well for September-March, but over-predicts the monthly averages in the late-spring and summer months (April-August). This is likely due to the fact that the distribution mapping caused a greater adjustment in extreme events which occur most often in the summer months in this watershed.

\subsubsection{Seasonal Amplitude}

The seasonal amplitude, computed as the difference between the wettest and driest month in each year, was calculated for all bias-corrected models and for the period 1971-2000. The averages across all years of these seasonal amplitudes can be found in Figure 10. The seasonal amplitude results varied across the models more than the results of the long-term monthly mean. For many of the models, the power transformation bias correction performed best when looking at the overall average of the seasonal amplitude (Figure 10), tending to just barely over-estimate the observed average. This is consistent with the purpose of the power transormation method, to correct the variance, which was not accounted for with the linear scaling and LOCI approaches. The LOCI bias correction typically performed second best, after power transformation, or best for some of the models. However, the overall average of seasonal variance was often an underestimate of the observations. The LOCI method uses the precipitation threshold in its approach, which contributed towards correcting some of the minimum precipitation values, and, therefore, was expected to perform better than the linear scaling approach and raw model. The linear scaling approach was often very similar in results to the raw model, showing almost no benefit in doing that bias correction from the perspective of correcting the variance, which is consistent with the goals of the method. For all but one model, the distribution mapping method performed the worst in correcting the variance, with the highest average seasonal variance of all methods. Again, this was an expected result because of the larger corrections made to high precpitation events in this method. Due to the shapes of the modeled and observed CDFs, many precipitation events were increased in the distribution mapping correction, which produced larger maximum monthly precipitation values, and, therefore, increased the variance, often largely over-predicting the observations. 


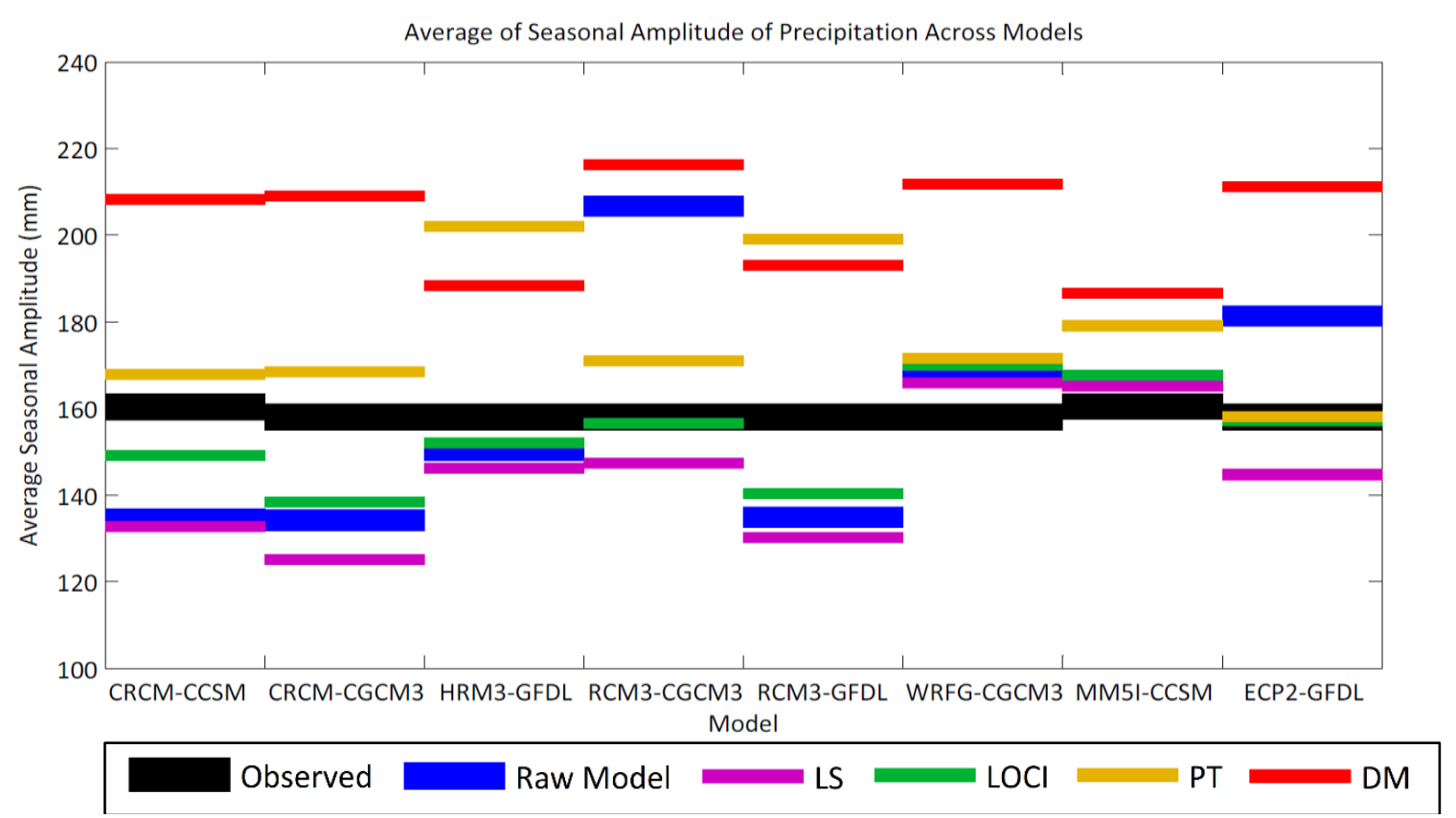

Figure 10. Overall averages of seasonal amplitude (for 1971-2000) for each model and their respective bias correction methods.

\subsubsection{Annual Precipitation}

The annual precipiation as the sum of all precipitation event during the year were also calculated for all raw and bias-corrected model predictions. Figure 11 shows the average of the annual precipitations over the 30 year period for each model and the bias corrections. For all but one of the models, the linear scaling bias correction best matched the observed average of annual precipitation. Because the linear scaling method only involves scaling the precipitation using a ratio of observed to modeled, this is an expected result. The LOCI approach also performed well for the average annual precipitation, just slightly over-predicting the observations for all the models, due to a similar scaling method. The power transformation method performed fairly well, following closely behind the linear scaling and LOCI bias corrections for most of the models, but almost always under-predicted the observations. Similar to the seasonal amplitude results, the distribution mapping method overpredicted across all models due to the CDF correction that led to high increases in the values of a large number of the precipitation data. 


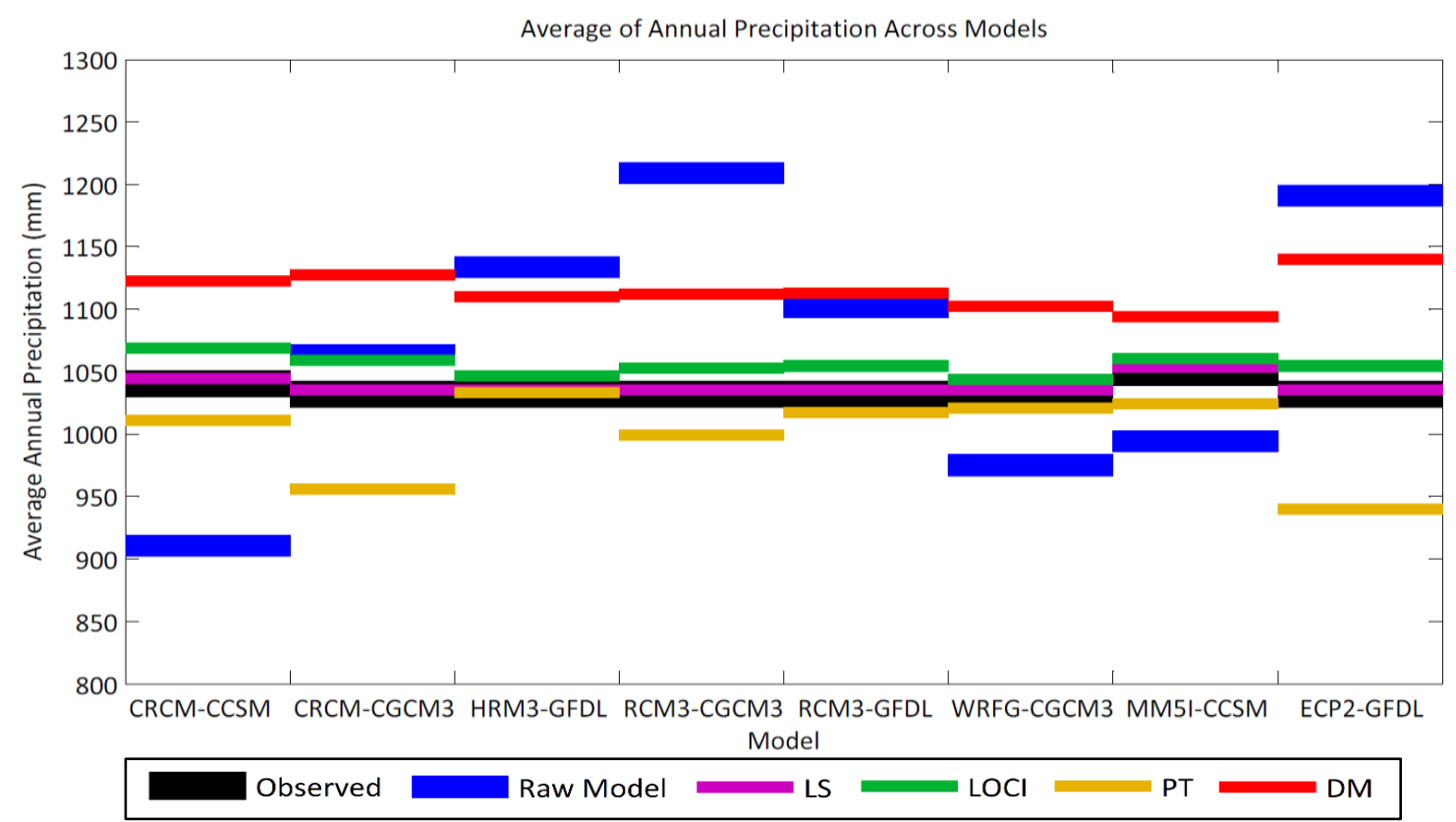

Figure 11. Averages of annual precipitation (for 1971-2000) for each model and their respective bias correction methods.

\subsubsection{Long-term Monthly Coefficient of Variation}

The long-term monthly coefficient of variation was computed for each month of the year, using all the monthly data for the respecitve month over the 30 year model period. The results for the CRCM-CCSM model are shown in Figure 12. The long-term monthly coefficient of variation results varied widely across all the models and bias correction methods. There is no clear method that is better than the others, as seen in the example for CRCM-CCSM in Figure 12Figure . Because the $\mathrm{CV}$ values vary so extremely from month to month, the seasonal averages of the standardized errors do not show any clear trends across the models. For most models, the raw model tended to underestimate the long-term monthly $\mathrm{CV}$ for most months. The linear scaling method again had the same results as the raw model due to the correction method. The LOCI bias correction seemed to predict a slightly higher value than the raw model and linear scaling method did, but still did not closely follow the trends in the observated data. Like the LOCI approach, the power transormation method produced slightly higher values that were closer to the observed values, but also tended to fluctuate slightly more from month to month. Similarly to the seasonal variance, the PT method was expected to better in correcting the variance than the two scaling approaches did. The distribution mapping approach resulted in the highest long-term 
monthly CV values compared to the other methods for most models, but did not closely follow the observed data.

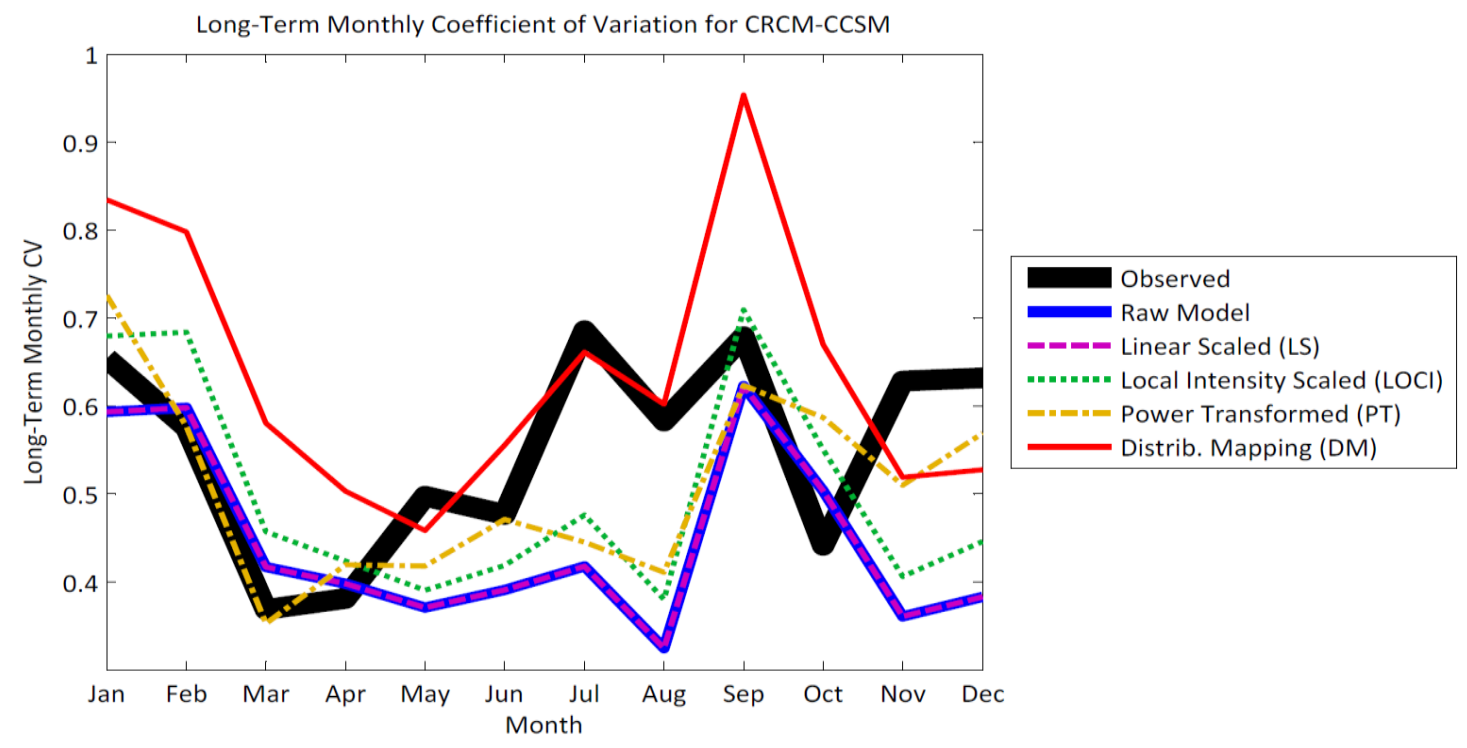

Figure 12. Long-term monthly coefficient of variation for precipitation for the CRCMCCSM model for 1971-1999. Calculated as the coefficient of variation of all monthly precipitation for the respective month over the 29 year period.

\subsubsection{Overall Annual Coefficient of Variation}

The overall coefficient of variation, using the annual precipitation over the 30 year model period, and the normalized error values (Eq. (16)) were then calculated for all the raw and bias-corrected models, as shown in Figure 13. Results on the overall coefficient of variation varied widely across all the models. As seen in Figure 13, there are no consistent trends for each bias correction method throughout all the models. The raw models, linear scaling, and LOCI bias corrections tend to under-predict the observed CV for most models, while the distribution mapping tends to over-predict the observed CV. This is mostly consistent with the results from the long-term monthly coefficient of variation. The power transformation method, depending on the model, both over- and under-predicted the observed CV. 


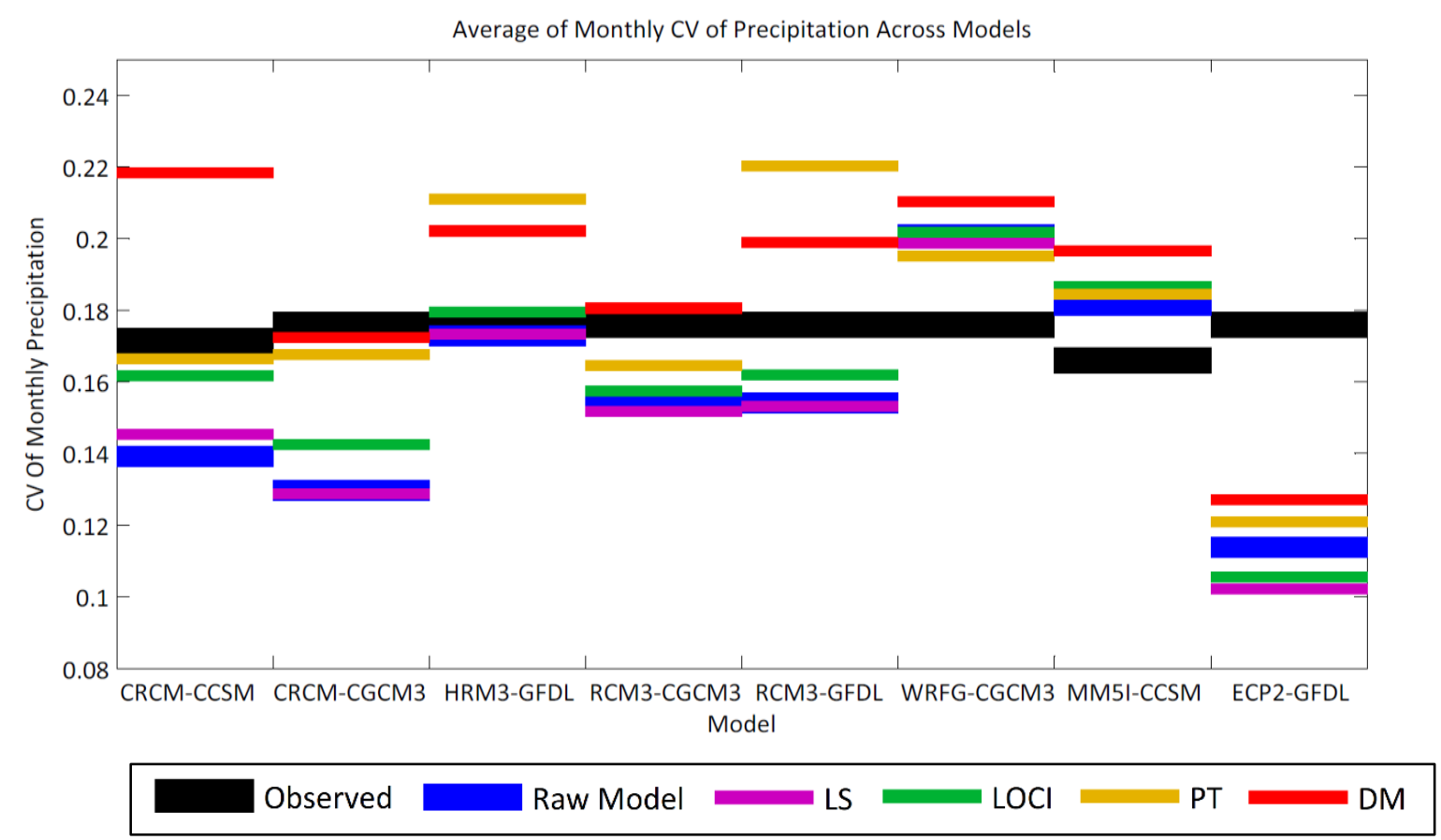

Figure 13. Overall coefficient of variation of annual precipitation (for 1971-2000) for each model and their respective bias correction methods.

\subsubsection{Ensemble Selection}

For each performance metric discussed above, the normalized error values for the model realizations were calculated and the absolute value of the normalized errors were summed up across the performance metrics. Table shows the total error for each of the 40 total model and bias correction outputs. After comparing the overall error, realizations were removed from the ensemble if their error was closer to the worst raw model error (an error of 2.19) than the best bias-corrected realization error (an error of 0.3), meaning any realization with an error of 1.24 or above was removed from the ensemble (gray cells in Table 5). Using this method, 13 realizations were removed and 27 realizations remained in the ensemble for further analysis.

Table 5. Overall errors for all model realizations (dark grey cells denote removed realization)

\begin{tabular}{l|llllllll}
\hline \multirow{2}{*}{ Model } & $\begin{array}{l}\text { CRCM- } \\
\text { CCSM }\end{array}$ & $\begin{array}{l}\text { CRCM- } \\
\text { CGCM3 }\end{array}$ & $\begin{array}{l}\text { HRM3- } \\
\text { GFDL }\end{array}$ & $\begin{array}{l}\text { RCM3- } \\
\text { CGCM3 }\end{array}$ & $\begin{array}{l}\text { RCM3- } \\
\text { GFDL }\end{array}$ & $\begin{array}{l}\text { WRFG- } \\
\text { CGCM3 }\end{array}$ & $\begin{array}{l}\text { MM5I- } \\
\text { CCSM }\end{array}$ & $\begin{array}{l}\text { ECP2- } \\
\text { GFDL }\end{array}$ \\
\hline RAW & 1.85 & 1.86 & 1.00 & 1.94 & 1.41 & 0.95 & 0.68 & 2.19 \\
LS & 1.02 & 1.43 & 0.50 & 0.69 & 1.09 & 0.52 & 0.30 & 1.15 \\
LOCI & 0.82 & 1.05 & 0.44 & 0.48 & 0.83 & 0.67 & 0.39 & 1.17 \\
PT & 0.62 & 1.13 & 0.58 & 0.93 & 1.70 & 0.76 & 0.88 & 1.40
\end{tabular}




\begin{tabular}{l|llllllll} 
DM & 1.98 & 1.72 & 1.09 & 1.48 & 1.23 & 1.77 & 1.04 & 3.02 \\
\hline
\end{tabular}

\subsection{Hydrological Model Calibration and Evaluation}

The SWAT model was calibrated for the "current" time period (2001-2012). After the calibration parameters (found in Table 3 and Table 4) were adjusted, the SWAT model predictions at outlet of sub-basin 70 near Zionsville was compared with the USGS station at Zionsville to calculate model performance. The best model was found to have a monthly Nash-Sutcliffe Efficiency (NSE) of 0.84 and monthly Square of Pearson's Product-Moment correlation coefficient $\left(\mathrm{R}^{2}\right)$ of 0.87. A NSE of 0.65 or greater is considered "very good" for the SWAT model according to Moriasi et al. (2007), so no further calibration was performed. The model tended to capture the general monthly streamflow trends, including baseflow and timing of peaks, which were observed over the 2001-2012 time period, but slightly under-predicted the streamflow peaks. The calibrated SWAT model performance was then evaluated for the "past" time period (1971-2000). The modeled streamflow when compared to the historic observed flow from the USGS, gave a monthly NSE of 0.56 and $\mathrm{R}^{2}$ of 0.63 , which are considered satisfactory or acceptable (Moriasi et al., 2007).

\subsection{Streamflow Analyses}

The modeled hindcast streamflow for each climate realization was analyzed by calculating the long-term monthly mean. Figure 14 depicts the long-term monthly mean of the observed streamflow at Zionsville USGS station (black dotted line), the modeled streamflow using observed climate (thick red line), and the modeled streamflow for each climate realization (colored lines). Some realizations followed the general trend of the streamflow from observed climate (red line), but others varied drastically in the overall trends or during specific months. The error boundary, set at \pm 3 times the standard error (Eq. (18)) for SWAT run with observed climate, is shown as the red dashed lines in Figure 14. All climate realizations that produced more than one month out of the error bounds were removed from the ensemble, to give a final ensemble of 11 realizations (i.e., CRCM-CCSM-LOCI, CRCM-CGCM3-LOCI, HRM3-GFDLLOCI, HRM3-GFDL-LS, MM5I-CCSM-DM, MM5I-CCSM-LOCI, MM5I-CCSM-LS, MM5ICCSM-RAW， RCM3-CGCM3-LOCI，WRFG-CGCM3-LOCI，WRFG-CGCM3-LS) that predicted streamflows representative of observed streamflows. This final ensemble of climate 
realizations when coupled with the SWAT model produce streamflow realizations that performed the best in October-December. Streamflows in January-February were slightly underpredicted for all of the 11 realizations, were over-predicted in March, and were more evenly split in under- and over-predicting during the spring and summer months. Similar observations were made when the long-term monthly cumulative distribution functions (CDFs) were fitted for streamflows predicted by the SWAT model with climate data from the 11 realizations, and were then compared against the CDF fitted to the SWAT-modeled streamflows using observed climate data. The streamflows from the climate model realizations tended to capture the distribution of the streamflow from climate observations very well. The distributions were best matched in the fall, winter and spring. The summer months showed a little more variation between realizations and differed slightly more from the streamflows predicted using observed climate.

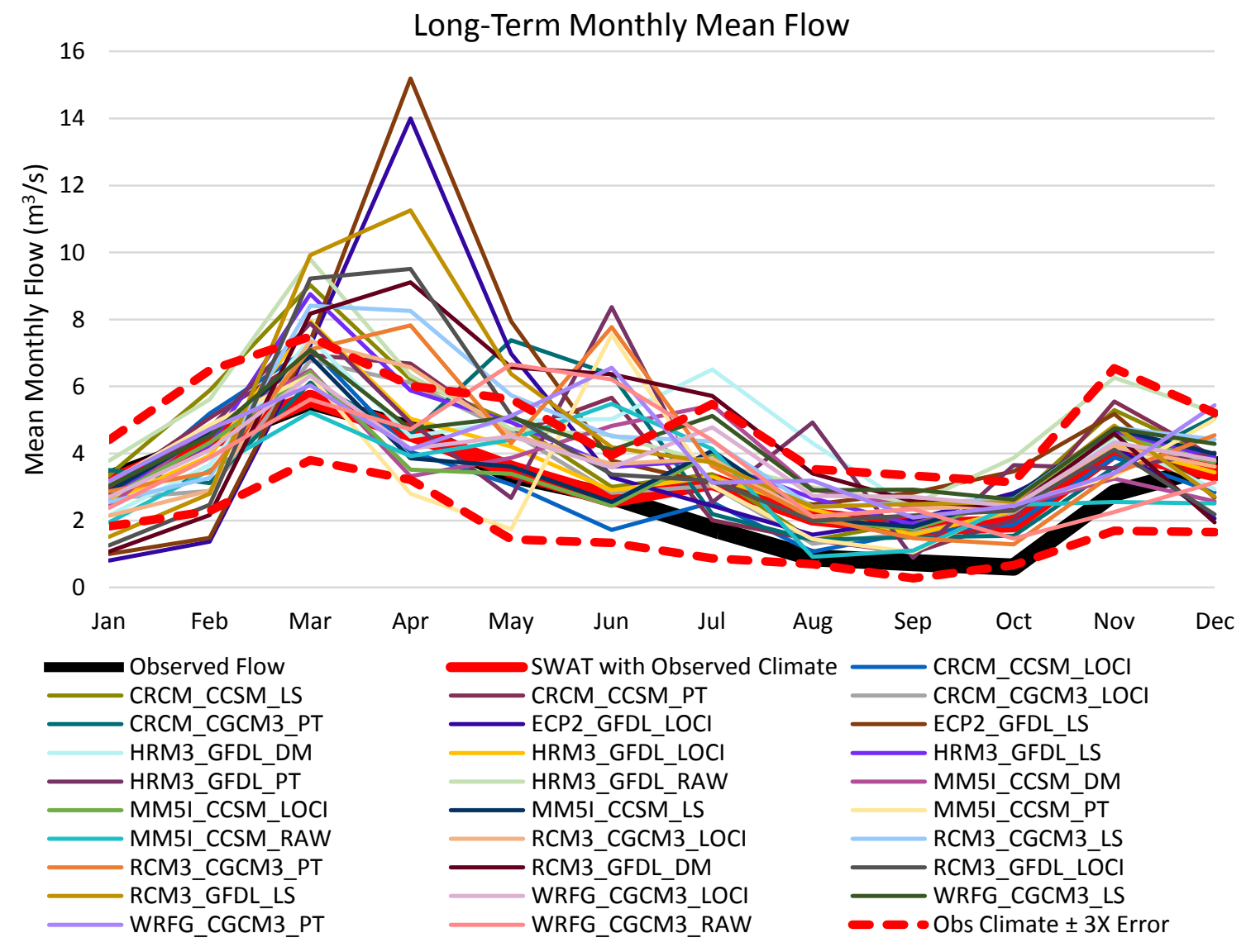

Figure 14. Long-term monthly mean (1971-2000) streamflows for observed streamflows, modeled streamflows from climate realizations, and modeled streamflows from observed climate data (including \pm 3 times standard error for modeled streamflow with observed climate). 


\subsection{Land Use Analyses}

To evaluate the effects of urban growth on streamflow, the calibrated SWAT model was run using the 2012 land use map and a projected urban growth land use map in the mid-century 2050 period. The maximum difference in resulting streamflows for each climate model in the final ensemble was found to range from 1.32 to $3.32 \mathrm{~m}^{3} / \mathrm{s}$, which are about $0.57 \%$ to $1.16 \%$ of the maximum resulting flow for the projected land use model run. As seen earlier in Figure 3, the major land use change predicted for central Indiana is urban growth. Because of the very minor differences in streamflows produced from projected land use in this watershed, land use projection map was discarded and the current 2012 land use map was used for the wetland analysis. This also indicates that the land transformation model used to create the "future" (i.e. mid-century 2050 period) land use was focused on drivers that changed urban land use, and did not predict any significant effect of climatic drivers on the crop types. While this might be a limitation of the land transformation model, it enabled us to focus on only the effects of the climate change related variables.

\subsection{Climate Change Analyses}

\subsubsection{Streamflow Analysis}

To compare seasonal trends in the streamflow from the past period to the future period, the longterm monthly mean streamflow was computed for the streamflow output in sub-basin 70 where the Zionsville USGS station is located. Figure 15 shows the long-term monthly mean flow for the future period. Compared to past streamflows of final realizations in Figure 13, the past and future time periods show similar trends with the highest streamflows occurring in March and the lowest in August. However, in the future (Figure 14), the climate scenarios tend to predict a wider range of streamflow values for each month, especially in the winter compared to the past, demonstrating more uncertainty with the future predictions. The future generally shows an increase in streamflow in the winter months (December, January, and February) and a decrease in March, November, and in the summer months (June, July and August). The majority of climate models predicted monthly streamflows to increase, from the past to future, up to about 1

$\mathrm{m}^{3} / \mathrm{s}$ in January and around $1-3 \mathrm{~m}^{3} / \mathrm{s}$ in November and December. In the past, all climate models anticipated a decrease in streamflow from November to December, but in the future, the majority of models showed an increase from November to December. In the future, many of the climate 
models predicted the lowest mean monthly streamflow of less than $1 \mathrm{~m}^{3} / \mathrm{s}$ in August, while in the past, the majority of the climate models predicted streamflow around $2-3 \mathrm{~m}^{3} / \mathrm{s}$ in August. Overall, these results show a slight increase in high flows and slight decrease in low flows, confirming predictions of more severe floods and droughts expected in the future. The general trends seen in the long-term monthly mean streamflow can be attributed to the precipitation data. In the future, a much higher variation across the climate realizations was found in the long-term monthly mean precipitation obtained after bias-correcting precipitation projections corresponding to the 11 final realizations. The future precipitation realizations also showed an increase in long-term monthly mean precipitation of up to $30 \mathrm{~mm}$ in the winter and spring, and a decrease of up to $25 \mathrm{~mm}$ in the summer.

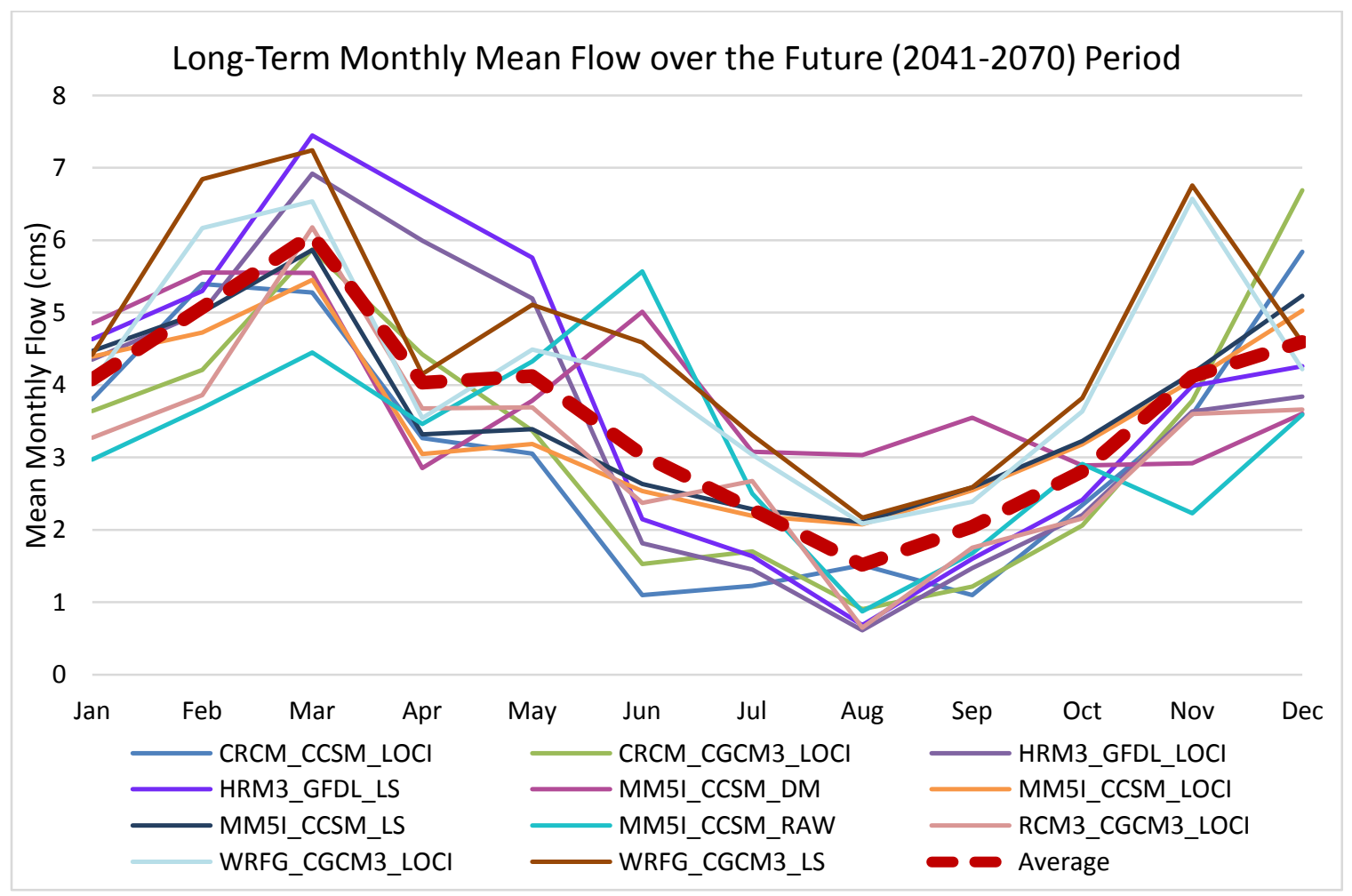

Figure 15. Long-term monthly mean streamflow over the future (2041-2070) period from sub-basin 70.

\subsubsection{Extreme Event Analysis of Flood Events}

The results in this section compare the streamflow output for the past time period of 1971-2000 with the future time period of 2041-2070, using climate projections from NARCCAP for both time periods. This analysis used the streamflow output from sub-basin 70, which was used for 
calibration and validation and is where the USGS Zionsville gage is located, and from sub-basin 110, located further downstream where the maximum peak flow reduction in the watershed occurred. The first component of the analysis examined the change in flood frequency. The number of days (expressed as a percent of all days) with streamflow equal to or greater than the Q05 streamflow value were computed for the past time period. The Q05 value was computed individually for each climate realization, so the past period had $5 \%$ of the days equal to or exceeding the Q05 value for all models, consistent with the definition of the Q05 streamflow. For both sub-basins, in the future, six coupled climate realization-SWAT models showed an increase in the number of days meeting or exceeding the historic Q05 value and five showed a decrease. For sub-basin 70 , the maximum increase at $5.38 \%$ was found when the SWAT model was coupled with WRFG-CGCM3-LOCI model, and the maximum decrease at $3.82 \%$ was found when the SWAT model was coupled with the RCM3-CGCM3-LOCI model. For sub-basin 110, the maximum increase was from the WRFG-CGCM3-LOCI and the WRFG-CGCM3-LS climate models at $5.77 \%$, and the maximum decease was from RCM3-CGCM3-LOCI at 3.91\%. These percent increases in number of days means that flow events of this magnitude or greater are predicted to be more frequent in the future as compared to the past.

Flood events were also compared by calculating the Q05 streamflow value for the future time period and compare that to the Q05 value from the past time period. In the past and for both subbasins, most climate model realizations (nine out of eleven) were found to over-predict the Q05 value calculated using the observed climate in the SWAT model. For sub-basin 70, the range of Q05 values in the past varied from 12 to $14.1 \mathrm{~m}^{3} / \mathrm{s}$ and the range increased in the future to 11.7 to $15 \mathrm{~m}^{3} / \mathrm{s}$, resulting in a slightly wider range in Q05 values for future climate projections. For subbasin 110, the range of Q05 values in the past varied from 16.3 to $19.2 \mathrm{~m}^{3} / \mathrm{s}$, but the range widened to 15.9 to $20.4 \mathrm{~m}^{3} / \mathrm{s}$ in the future. In sub-basin 70 and 110 , six of the climate realizations predicted an increase in the Q05 flow magnitudes in the future and five realizations predicted a decrease in the Q05 flow values. Based on these results, it is unclear whether these high flow events will increase or decrease in magnitude.

In addition to the high flow frequency and magnitudes, the seasonal distribution of high flow events was also analyzed. The number of streamflow events equal to or exceeding the Q05 value occurring in each respective month, expressed as a percentage of all Q05 or greater streamflow 
events were calculated for sub-basins 70 and 110 (also shown in Figure 16 as an example for sub-basin 110). The filled circles in Figure 15 denote the percent of high flow events occurring in the month for the past time period and the open circles denote the occurrence in the future time period. The climate model realizations show agreement in the direction of change for some months, often occurring when magnitudes of change are large, but also show conflicts in the direction of change for other months, mostly when magnitudes of change are small. For both sub-basins, December and January showed an increase in frequency of high flow events across all models, meaning that more high flow events are expected to occur in the winter. February shows a mix of increased and decreased frequencies, but all of very small magnitude, meaning that the expected occurrence of high flow events will not change much. March, which contains the highest frequency of high flow events, showed a much larger magnitude decrease in frequency expected in the future. The spring and fall seasons, April, May, June, August, September, October, and November, showed a mixture of increased and decreased frequency projections of relatively small magnitude. July shows a mid-summer expected decrease in frequency of high flow events. Overall, high flow events are anticipated to increase in frequency in the winter and decrease in the spring and summer. 

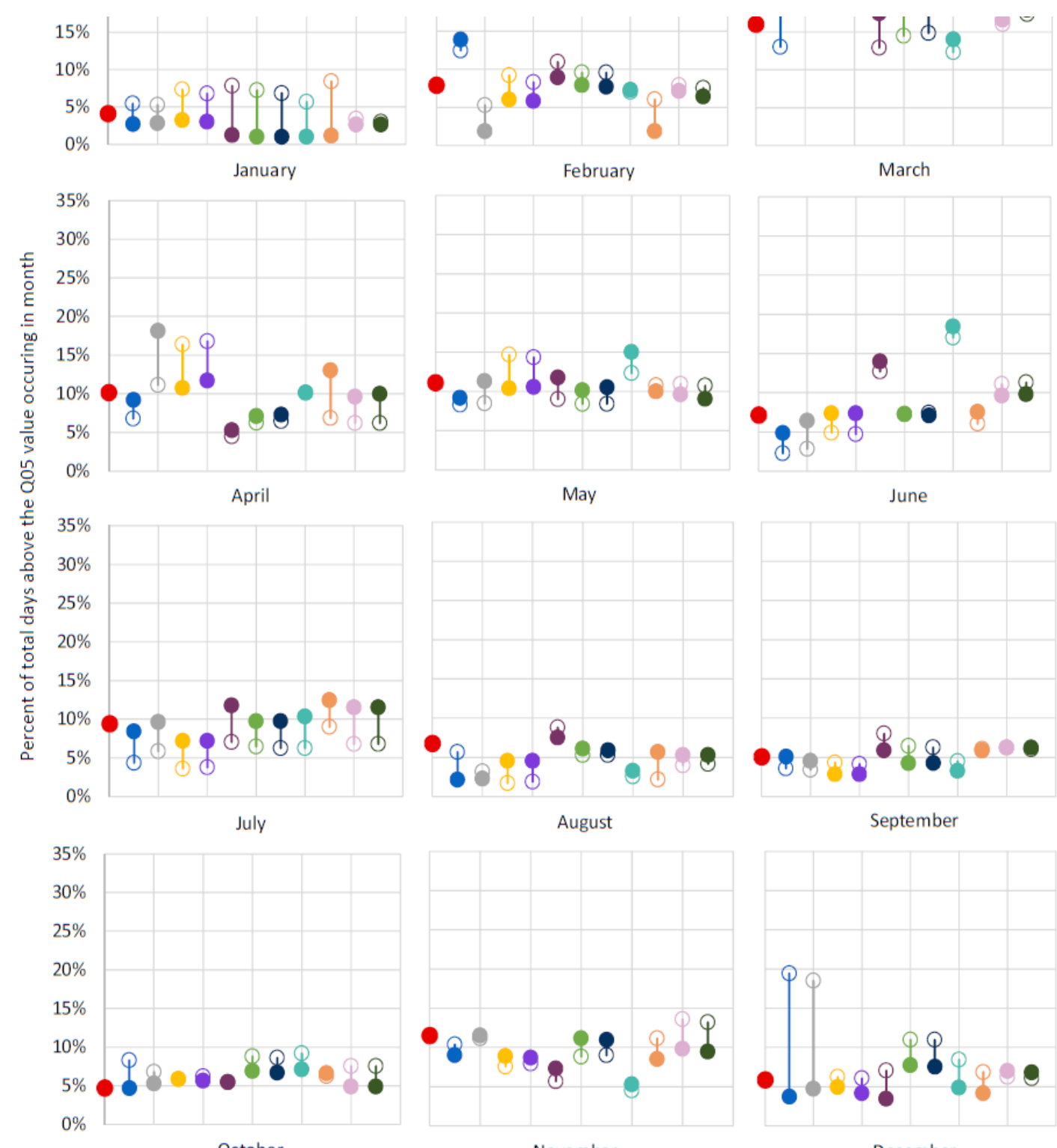

Figure 16. Seasonal distribution of streamflow events equal to or exceeding the Q05 streamflow value for the past (1971-2000) time period (filled circles) and future (2041-2070) time period (open circles) for sub-basin 110.

\subsection{Wetland Analyses}

The wetland analysis consisted of an extreme event analysis and a peak flow reduction analysis. The flood events were analyzed for streamflows predicted from SWAT model cases with and without potential wetlands and for both the past and future time periods. The streamflow outputs from sub-basins 70 and 110 were used as examples to analyze the benefits obtained by installing and restoring wetlands in the entire watershed. 


\subsubsection{Extreme Event Analysis of Flood Events}

The Q05 streamflow value was calculated for the "no wetlands" and "wetlands" cases, and for the past time (1971-2000) and future time periods (2041-2070). For both time periods, all climate model realizations based SWAT models predicted an expected decrease in the Q05 streamflow value when wetlands are installed. For sub-basin 70, the estimated decrease in past Q05 values ranged from 0.58 to $1 \mathrm{~m}^{3} / \mathrm{s}$ across the climate ensembles, and estimated decrease in future Q05 values had a similar range of 0.53 to $1 \mathrm{~m}^{3} / \mathrm{s}$. The average reduction in the Q05 value for the past time period was $0.73 \mathrm{~m}^{3} / \mathrm{s}$ and the average reduction for the future time period had a similar magnitude of $0.77 \mathrm{~m}^{3} / \mathrm{s}$. For sub-basin 110, the decrease in Q05 values across all climate ensemble ranged from 0.65 to $1.3 \mathrm{~m}^{3} / \mathrm{s}$ in the past, and ranged from 0.61 to $1.53 \mathrm{~m}^{3} / \mathrm{s}$ for the future. The average reduction in the Q05 value for the past time period was $0.93 \mathrm{~m}^{3} / \mathrm{s}$ and the average reduction for the future time period was also similar with a magnitude of $0.99 \mathrm{~m}^{3} / \mathrm{s}$. This indicates that if all the potential wetlands identified by Babbar-Sebens et al. (2013) had been installed or restored in the watershed then Q05 events would have been less severe in the past. Additionally, in the future, though the climate ensemble based SWAT model results predicted both increased and decreased frequency of high flow events (Section 4.5.2), but in all cases, the installation and restoration of the wetlands was found to have similar reduction in magnitude of high flow events.

\subsubsection{Peak Flow Reduction Analysis}

To evaluate the reduction in peak flows by wetlands, the maximum peak flow reduction (PFR) was calculated by Eq. (19). The maximum reduction in peak flow across all 30 years and all subbasins was calculated for each climate model realization for both the past and future time periods. The resulting maximum peak flow reduction for each climate model realization is shown in Table 6. Also shown in the table is the maximum peak flow reduction as a percentage of the peak flow for the "no wetlands" case. The average reduction seen when wetlands are installed for the past time period is $42.1 \mathrm{~m}^{3} / \mathrm{s}$, and $35.2 \mathrm{~m}^{3} / \mathrm{s}$ in the future, with standard deviations of 11.7 and 6.9, respectively. The maximum peak flow reductions range from 20.3 to $60.3 \mathrm{~m}^{3} / \mathrm{s}$ and occurred in sub-basin 110 for each climate model realization. This shows that wetlands could have reduced peak flows and floods by over $40 \mathrm{~m}^{3} / \mathrm{s}$ if wetlands had been installed in all of the potential locations in the past. In the future, just slightly smaller benefits are predicted from the 
models. Installing wetlands may reduce future peak flows by around 24 to $44 \mathrm{~m}^{3} / \mathrm{s}$. The wetlands produced maximum peak flow reductions that ranged from $15-20 \%$ of the peak flow without the wetlands. The average reduction was $17.6 \%$ in the past and $18.8 \%$ in the future.

Table 6. Maximum peak flow reduction $(\mathrm{PFR})\left(\mathrm{m}^{3} / \mathrm{s}\right)$, and peak flow reduction as a percent of the peak flow without wetlands, for each climate model realization for both the past (1971-2000) and future (2041-2070) time periods.

\begin{tabular}{lllll}
\hline \multicolumn{1}{l}{} & $\begin{array}{l}\text { MAX } \\
\text { PFR } \\
\text { MODEL }\end{array}$ & $\begin{array}{l}\text { \% PFR } \\
\text { (PAST) }\end{array}$ & $\begin{array}{l}\text { MAX PFR } \\
\text { (M } / \text { /S) } \\
\text { (PAST) }\end{array}$ & $\begin{array}{l}\text { \% PFR } \\
\text { (FUTURE) }\end{array}$ \\
\hline CRCM_CCSM_LOCI & 28 & $19.0 \%$ & 23.8 & $18.0 \%$ \\
CRCM_CGCM3_LOCI & 20.3 & $16.9 \%$ & 40.8 & $18.3 \%$ \\
HRM3_GFDL_LOCI & 42.8 & $16.2 \%$ & 43.7 & $19.3 \%$ \\
HRM3_GFDL_LS & 41.3 & $16.2 \%$ & 42.8 & $19.3 \%$ \\
MM5I_CCSM_DM & 60.3 & $15.2 \%$ & 35.4 & $15.2 \%$ \\
MM5I_CCSM_LOCI & 53.1 & $17.4 \%$ & 32.3 & $19.6 \%$ \\
MM5I_CCSM_LS & 52.8 & $17.5 \%$ & 31.2 & $19.5 \%$ \\
MM5I_CCSM_RAW & 47.6 & $18.4 \%$ & 32.6 & $17.1 \%$ \\
RCM3_CGCM3_LOCI & 32.6 & $18.2 \%$ & 24.6 & $19.1 \%$ \\
WRFG_CGCM3_LOCI & 42.5 & $19.0 \%$ & 40.3 & $20.4 \%$ \\
WRFG_CGCM3_LS & 42.1 & $19.0 \%$ & 39.4 & $20.4 \%$ \\
\hline AVERAGE & 42.13 & $17.56 \%$ & 35.17 & $18.76 \%$ \\
Standard deviation & 11.67 & $1.32 \%$ & 6.92 & $1.53 \%$ \\
Coefficient of variation & 0.277 & 0.075 & 0.197 & 0.081 \\
\hline
\end{tabular}

Robustness in a solution means that the alternative achieves the desired goals and is insensitive to uncertainties (Dessai \& Hulme, 2007; Hashimoto, Stedinger, \& Loucks, 1982). Calculating the standard deviation across scenarios gives an measure of the robustness of an alternative (Watkins Jr \& McKinney, 1997). The peak flow reductions in Table 6 show peak flow reductions in the future are similar to the peak flow reductions that would have been seen in the past, telling us that performance of the potential wetlands would be consistent in the future. The expected maximum peak flow reductions are also very similar across the climate realizations, showing that wetland performance is insensitive to individual climate projections. The standard deviations are moderately low, meaning there is relatively low variance between the climate realizations. The robustness was also measured with the coefficient of variation. The future 
showed a smaller coefficient of variation than the past due to the lower variation between climate realizations, telling us that wetlands are a little more reliable in the future.

To further examine the robustness of wetlands as a solution for peak flow reduction, reductions in flows within certain ranges were also analyzed. The maximum peak flow reductions above typically occurred at higher streamflows, around $100 \mathrm{~m}^{3} / \mathrm{s}$ or higher. These higher streamflows also showed a higher standard deviation of average peak flow reductions across the climate models. The medium and lower flows, however, had very small standard deviations of peak flow reduction across the models. This means that all of the climate realizations predicted very similar peak flow reductions for medium and lower streamflows. Table shows the average reduction for streamflows within a range for each climate model, the average across climate models, the standard deviations, and the coefficients of variation, for the future period (2041-2070). Above $150 \mathrm{~m}^{3} / \mathrm{s}$, the models project more variation in the anticipated streamflow reduction, as seen with the higher standard deviation of 4.2, and the much higher coefficient of variation. The low standard deviations and coefficients of variation for the remaining lower streamflow ranges mean that all the climate models closely agree with the projected flow reductions. For streamflows between $50-100 \mathrm{~m}^{3} / \mathrm{s}$, a higher average reduction is found when wetlands are implemented, but the variation across the climate realizations is very small, resulting in the lowest coefficient of variation. This shows that wetlands are the most robust for streamflow between $50-100 \mathrm{~m}^{3} / \mathrm{s}$, followed by streamflow between $0-50 \mathrm{~m}^{3} / \mathrm{s}$, and then $100-150 \mathrm{~m}^{3} / \mathrm{s}$. The wetlands show the most robustness, or reliability, in peak flow reduction for streamflows up to $150 \mathrm{~m}^{3} / \mathrm{s}$. This means that no matter which climate projection occurs, a similar peak flow reduction can be expected.

Table 7. Average peak flow reductions for streamflows within given ranges for 2041-2070.

\begin{tabular}{|c|c|c|c|c|}
\hline \multirow[b]{2}{*}{ MODEL } & \multicolumn{4}{|c|}{ AVG. STREAMFLOW REDUCTIONS FOR FLOWS } \\
\hline & $\begin{array}{l}\text { IN R } \\
150+\end{array}$ & $\left.M^{3} / S\right) 0-50$ & 50- & 100-150 \\
\hline CRCM_CCSM_LOCI & 0.256 & 6.991 & 9.702 & 5.750 \\
\hline CRCM_CGCM3_LOCI & 0.232 & 6.499 & 11.952 & 19.833 \\
\hline HRM3_GFDL_LOCI & 0.260 & 6.579 & 10.829 & 12.720 \\
\hline HRM3_GFDL_LS & 0.240 & 6.491 & 10.524 & 12.933 \\
\hline MM5I_CCSM_DM & 0.291 & 7.311 & 9.903 & 12.163 \\
\hline MM5I_CCSM_LOCI & 0.282 & 6.896 & 11.200 & 13.736 \\
\hline MM5I_CCSM_LS & 0.272 & 6.886 & 10.821 & 13.373 \\
\hline MM5I_CCSM_RAW & 0.267 & 7.190 & 9.953 & 11.650 \\
\hline
\end{tabular}




\begin{tabular}{l|llll} 
RCM3_CGCM3_LOCI & 0.229 & 6.960 & 10.942 & 5.500 \\
WRFG_CGCM3_LOCI & 0.259 & 6.439 & 10.615 & 16.419 \\
WRFG_CGCM3_LS & 0.245 & 6.664 & 10.329 & 16.078 \\
\hline Average & 0.258 & 6.81 & 10.62 & 12.74 \\
Standard deviation & 0.0199 & 0.2956 & 0.6476 & 4.2334 \\
Coefficient of variation & 0.077 & 0.043 & 0.061 & 0.332 \\
\hline
\end{tabular}

\section{CONCLUSIONS}

This study used the SWAT hydrological model forced with an ensemble of bias corrected climate projection outputs from NARCCAP to conduct a long-term assessment of the performance of potential wetlands in their ability to reduce high streamflows in the future, as well as to evaluate changes in extreme events expected for the future as compared to the past. The analysis performed in this research focused on the Eagle Creek Watershed in Indiana as a case study, and built on the previous study by Babbar-Sebens et al. (2013) that had identified 2953 potential wetland locations in 108 of the 130 sub-basins.

In using the RCM-AOGCM model output for a hydrological impact study, it was found that the minimum and maximum temperatures for the watershed were well simulated by the climate models. However, the climate models did not accurately represent the variance and seasonal trends in precipitation for the watershed, confirming findings from previous studies showing the necessity for bias correction of precipitation projection outputs. Four bias correction approaches and the raw climate models, resulting in 40 climate realizations, were investigated and evaluated for several error metrics. The bias correction methods that did not improve the precipitation data were removed, leaving 27 climate realizations, which was further narrowed down to 11 realizations with a streamflow analysis in SWAT.

The final ensemble of climate realizations was input into the calibrated SWAT model to simulate watershed hydrology in projected future climate scenarios. A land use change analysis was performed to estimate the impacts of urban development on streamflow. Urban growth projections for 2050 produced very minimal effects on streamflow output for the future time period (2041-2070) and were, hence, not incorporated into the subsequent analyses. The hydrological response to the future climate projections (2041-2070) was also compared to that of the past climate projections (1971-2000) in a streamflow analysis and an extreme event analysis. 
In general, the climate models predicted a slight increase in long-term mean monthly streamflow in the winter and a slight decrease in the summer from past to future. The extreme event analysis results showed that out of the 11 climate realizations, 6 projected an increase in the frequency of the historic Q05 value and 5 projected an expected decrease in the future. The ensemble tended to agree that overall, high flow events are anticipated to increase in frequency in the winter and decrease in the spring and summer.

The performance of potential wetlands was evaluated with an extreme event analysis and a peak flow reduction analysis. For both the past and future time periods, implementation of wetlands resulted in a reduction in the magnitude of the $5 \%$ exceedance streamflow (Q05) value of about 0.5-1.5 $\mathrm{m}^{3} / \mathrm{s}$ across all climate realizations. While it was shown that the high flow events would decrease in size, very little change in the seasonal distribution of the Q05 events was seen with the wetlands. The maximum peak flow reduction was calculated across all sub-basins in the watershed for each climate realization. When wetlands were implemented, the watershed saw maximum peak flow reductions between 20 and $60 \mathrm{~m}^{3} / \mathrm{s}$ in the past time period and 24 to $44 \mathrm{~m}^{3} / \mathrm{s}$ in the future, or $15-20 \%$ of the peak flow without wetlands in the past and $15-19 \%$ in the future. The distributions of peak flows above the Q05 streamflow value was also assessed. When wetlands were implemented, the median value, or event with a probability of occurrence of 0.5 , saw a decrease in magnitude of 0.85 to $2.25 \mathrm{~m}^{3} / \mathrm{s}$. This reduction means that, overall, the size of events expected at certain frequencies will be reduced when wetlands are installed, or that the frequency of high peak flow events will be reduced.

Wetlands were found to be a reliable alternative to reducing peak flows. The peak flow reductions in the future time period were similar to the reductions that would have occurred if wetlands had been implemented in the past, showing that wetlands performance will be consistent in the future. The robustness of wetlands as a method for peak flow reduction was analyzed. Robustness is defined as a solution that meets the desired goals while being insensitive to uncertainties, or in this case, the variance across the climate realizations. The expected maximum peak flow reductions were similar across all climate realizations, which tells us that they are insensitive to the climate projections. To further analyze the robustness of the wetlands, streamflow reductions were analyzed across models within certain ranges. Streamflows within 0$50 \mathrm{~m}^{3} / \mathrm{s}, 50-100 \mathrm{~m}^{3} / \mathrm{s}$, and $100-150 \mathrm{~m}^{3} / \mathrm{s}$, produced very similar streamflow reductions across the 
climate realizations. More variation in expected streamflow reductions occurred for streamflows above $150 \mathrm{~m}^{3} / \mathrm{s}$, but for the majority of flows, which occur below $150 \mathrm{~m}^{3} / \mathrm{s}$, wetlands show a robustness, or insensitivity to the climate projections.

Managing the expected changes in streamflow due to climate changes is a challenge and has become more important as flows increase in magnitude and frequency. Wetlands creation is a key strategy in management plans designed to withstand the effects of climate change and provide streamflow management benefits. This study focused on long-term projection of wetland performance for reducing peak flows and wetlands were found to reduce both the magnitude and frequency of peak flow events. By implementing wetlands occupying about $1.5 \%$ of the watershed, maximum peak flow reductions of 15-20\% can be obtained. This study highlights the benefits gained from wetlands in flood conditions and reinforces the need to for climate changeintegrated conservation plans. The methods established here can be applied to other watersheds or other conservations practices to conduct better long-term land management studies and decisions.

\section{ACKNOWLEDGEMENTS}

We would like to thank the National Science Foundation (Award ID: 1014693 and 1332385) and National Oceanic and Atmospheric Administration (NOAA/CPO/SARP; Award ID NA14OAR4310253) for funding portions of this research. We also wish to thank the North American Regional Climate Change Assessment Program (NARCCAP) for providing the model outputs used in this paper. NARCCAP is funded by the National Science Foundation (NSF), the U.S. Department of Energy (DoE), the National Oceanic and Atmospheric Administration (NOAA), and the U.S. Environmental Protection Agency Office of Research and Development (EPA).

\section{REFERENCES}

Arnell, N. W. (1999). The effect of climate change on hydrological regimes in Europe: a continental perspective. Global Environmental Change, 9(1), 5-23. doi:10.1016/S09593780(98)00015-6 
Arnold, J. G., Srinivasan, R., Muttiah, R. S., \& Williams, J. R. (1998). Large area hydrologic modeling and assessment part I: Model development1. JAWRA Journal of the American Water Resources Association, 34(1), 73-89.

Babbar-Sebens, M., Barr, R. C., Tedesco, L. P., \& Anderson, M. (2013). Spatial identification and optimization of upland wetlands in agricultural watersheds. Ecological Engineering, 52, 130-142. doi:10.1016/j.ecoleng.2012.12.085

Bergstrom, S., Carlsson, B., Gardelin, M., Lindstrom, G., Pettersson, A., \& Rummukainen, M. (2001). Climate change impacts on runoff in Sweden-assessments by global climate models, dynamical downscaling and hydrological modelling. Climate Research, 16(2), $101-112$.

Block, P. J., Souza Filho, F. A., Sun, L., \& Kwon, H.-H. (2009). A Streamflow Forecasting Framework using Multiple Climate and Hydrological Models1. JAWRA Journal of the American Water Resources Association, 45(4), 828-843.

Burkett, V., \& Kusler, J. (2000). Climate Change: Potential Impacts and Interactions in Wetlands of the United States. JAWRA Journal of the American Water Resources Association, 36(2), 313-320. doi:10.1111/j.1752-1688.2000.tb04270.x

Christensen, J. H., Boberg, F., Christensen, O. B., \& Lucas-Picher, P. (2008). On the need for bias correction of regional climate change projections of temperature and precipitation. Geophysical Research Letters, 35(20). Retrieved from http://www.agu.org/pubs/crossref/2008/2008GL035694.shtml

Clark, G. D. (Ed. . (1980). The Indiana Water Resource - Availability, Uses, and Needs. Governor's Water Resource Study Commission, State of Indiana, Indiana Department of Natural Resources.

Dessai, S., \& Hulme, M. (2007). Assessing the robustness of adaptation decisions to climate change uncertainties: A case study on water resources management in the East of England. Global Environmental Change, 17(1), 59-72. doi:10.1016/j.gloenvcha.2006.11.005

Dile, Y. T., \& Srinivasan, R. (2014). Evaluation of CFSR climate data for hydrologic prediction in data-scarce watersheds: an application in the Blue Nile River Basin. JAWRA Journal of the American Water Resources Association, n/a-n/a. doi:10.1111/jawr.12182

Eagle Creek Watershed Alliance. (n.d.). Eagle Creek Watershed Alliance. Retrieved from http://uwrwa.org/eaglecreek/index.html

Erwin, K. L. (2009). Wetlands and global climate change: the role of wetland restoration in a changing world. Wetlands Ecology and Management, 17(1), 71-84. doi:10.1007/s11273008-9119-1

Federal Emergency Management Agency (FEMA). (2014). Disaster Declarations by Year or State. Retrieved from http://www.fema.gov/disasters/grid/state-tribal-government

Fowler, H. J., Blenkinsop, S., \& Tebaldi, C. (2007). Linking climate change modelling to impacts studies: recent advances in downscaling techniques for hydrological modelling. International Journal of Climatology, 27(12), 1547-1578. doi:10.1002/joc.1556 
Gosain, A. K., Rao, S., \& Basuray, D. (2006). Climate change impact assessment on hydrology of Indian river basins. Current Science, 90(3), 346-353.

Grillakis, M. G., Koutroulis, A. G., \& Tsanis, I. K. (2011). Climate change impact on the hydrology of Spencer Creek watershed in Southern Ontario, Canada. Journal of Hydrology, 409(1-2), 1-19. doi:10.1016/j.jhydrol.2011.06.018

Grotch, S. L., \& MacCracken, M. C. (1991). The Use of General Circulation Models to Predict Regional Climatic Change. Journal of Climate, 4(3), 286-303. doi:10.1175/15200442(1991)004<0286:TUOGCM>2.0.CO;2

Hannah, L., Midgley, G. F., \& Millar, D. (2002). Climate change-integrated conservation strategies. Global Ecology and Biogeography, 11(6), 485-495. doi:10.1046/j.1466822X.2002.00306.X

Harris, J. A., Hobbs, R. J., Higgs, E., \& Aronson, J. (2006). Ecological Restoration and Global Climate Change. Restoration Ecology, 14(2), 170-176. doi:10.1111/j.1526100X.2006.00136.x

Hartig, E. K., Grozev, O., \& Rosenzweig, C. (1997). CLIMATE CHANGE, AGRICULTURE AND WETLANDS IN EASTERN EUROPE: VULNERABILITY, ADAPTATION AND POLICY. Climatic Change, 36(1-2), 107-121. doi:10.1023/A:1005304816660

Hashimoto, T., Stedinger, J. R., \& Loucks, D. P. (1982). Reliability, resiliency, and vulnerability criteria for water resource system performance evaluation. Water Resources Research, 18(1), 14-20. doi:10.1029/WR018i001p00014

Heisel, E. J. (2009). RIVER RESTORATION FOR WILDLIFE AND FLOOD REDUCTION. Finding the Balance between Floods, Flood Protection, and River Navigation, Published by Saint Louis University, 61.

Hey, D., Kostel, J., \& Montgomery, D. (2009). An ecological solution to the flood damage problem. Finding the Balance between Floods, Flood Protection, and River Navigation, Published by Saint Louis University, 72.

Ines, A. V. M., \& Hansen, J. W. (2006). Bias correction of daily GCM rainfall for crop simulation studies. Agricultural and Forest Meteorology, 138(1-4), 44-53. doi:10.1016/j.agrformet.2006.03.009

IPCC, 2014: Climate Change 2014: Synthesis Report. Contribution of Working Groups I, II and III to the Fifth Assessment Report of the Intergovernmental Panel on Climate Change [Core Writing Team, R.K. Pachauri and L.A. Meyer (eds.)]. IPCC, Geneva, Switzerland, 151 pp.

Jha, M., Arnold, J. G., Gassman, P. W., Giorgi, F., \& Gu, R. R. (2006). CLIMATE CHANGE SENSITIVITY ASSESSMENT ON UPPER MISSISSIPPI RIVER BASIN STREAMFLOWS USING SWAT. JAWRA Journal of the American Water Resources Association, 42(4), 997-1015.

Johnson, W. C., Millett, B. V., Gilmanov, T., Voldseth, R. A., Guntenspergen, G. R., \& Naugle, D. E. (2005). Vulnerability of Northern Prairie Wetlands to Climate Change. BioScience, 55(10), 863-872. doi:10.1641/0006-3568(2005)055[0863:VONPWT]2.0.CO;2 
Katz, R. W. (1999). Extreme value theory for precipitation: Sensitivity analysis for climate change. Advances in Water Resources, 23(2), 133-139.

Keddy, P. A. (2010). Wetland Ecology: Principles and Conservation. Cambridge University Press.

Lafon, T., Dadson, S., Buys, G., \& Prudhomme, C. (2013). Bias correction of daily precipitation simulated by a regional climate model: a comparison of methods. International Journal of Climatology, 33(6), 1367-1381. doi:10.1002/joc.3518

Leander, R., \& Buishand, T. A. (2007). Resampling of regional climate model output for the simulation of extreme river flows. Journal of Hydrology, 332(3-4), 487-496. doi:10.1016/j.jhydrol.2006.08.006

Leander, R., Buishand, T. A., van den Hurk, B. J. J. M., \& de Wit, M. J. M. (2008). Estimated changes in flood quantiles of the river Meuse from resampling of regional climate model output. Journal of Hydrology, 351(3-4), 331-343. doi:10.1016/j.jhydrol.2007.12.020

Lenderink, G., Buishand, A., \& Deursen, W. van. (2007). Estimates of future discharges of the river Rhine using two scenario methodologies: direct versus delta approach. Hydrology and Earth System Sciences, 11(3), 1145-1159.

Mearns, L. O. (2007, updated 2012). The North American Regional Climate Change Assessment Program dataset. Boulder, CO: National Center for Atmospheric Research Earth System Grid data portal. Retrieved from doi:10.5065/D6RN35ST

Mearns, L. O., Gutowski, W., Jones, R., Leung, R., McGinnis, S., Nunes, A., \& Qian, Y. (2009). A regional climate change assessment program for North America. Eos, Transactions American Geophysical Union, 90(36), 311-311.

Mitsch, W. J., \& Day Jr., J. W. (2006). Restoration of wetlands in the Mississippi-OhioMissouri (MOM) River Basin: Experience and needed research. Ecological Engineering, 26(1), 55-69. doi:10.1016/j.ecoleng.2005.09.005

Moriasi, D. N., Arnold, J. G., Van Liew, M. W., Bingner, R. L., Harmel, R. D., \& Veith, T. L. (2007). Model evaluation guidelines for systematic quantification of accuracy in watershed simulations. Trans. ASABE, 50(3), 885-900.

Moshiri, G. A. (1993). Constructed Wetlands for Water Quality Improvement. CRC Press.

Mulholland, P. J., Best, G. R., Coutant, C. C., Hornberger, G. M., Meyer, J. L., Robinson, P. J., ... Wetzel, R. G. (1997). Effects of Climate Change on Freshwater Ecosystems of the South-Eastern United States and the Gulf Coast of Mexico. Hydrological Processes, 11(8), 949-970. doi:10.1002/(SICI)1099-1085(19970630)11:8<949::AID-

HYP513>3.0.CO;2-G

Munasinghe, M., \& Swart, R. (2005). Primer on Climate Change and Sustainable Development: Facts, Policy Analysis, and Applications. Cambridge University Press.

Nakicenovic, N., \& Swart, R. (2000). Special report on emissions scenarios. Special Report on Emissions Scenarios, Edited by Nebojsa Nakicenovic and Robert Swart, Pp. 612. ISBN 0521804930. Cambridge, UK: Cambridge University Press, July 2000., 1. Retrieved from http://adsabs.harvard.edu/abs/2000sres.book.....N\%EF\%BF\%BD\%C3\%9C 
Nash, J. E., \& Sutcliffe, J. V. (1970). River flow forecasting through conceptual models part I A discussion of principles. Journal of Hydrology, 10(3), 282-290. doi:10.1016/00221694(70)90255-6

National Land Transformation Model. (2013). Human-Environment Modeling \& Analysis Laboratory, Department of Forestry and Natural Resources, Purdue University. Retrieved from http://ltm.agriculture.purdue.edu/usgs.htm

Natural Resources Defense Council (NRDC). (2012). Climate Change Health Threats in Indiana. Climate Change Threatens Health. Retrieved from http://www.nrdc.org/health/climate/in.asp

Neitsch, S. L., Arnold, J. G., Kiniry, J. R., \& Williams, J. R. (2011). Soil and Water Assessment Tool Theoretical Documentation, Version 2009. College Station, Texas: Grassland, Soil and Water Research Laboratory - Agricultural Research Service, USDA and Backland Research Center - Texas AgriLife Research, Texas A\&M University. Retrieved from Available at http://swat.tamu.edu/documentation/

Piani, C., Haerter, J. O., \& Coppola, E. (2010). Statistical bias correction for daily precipitation in regional climate models over Europe. Theoretical and Applied Climatology, 99(1-2), 187-192. doi:10.1007/s00704-009-0134-9

Piemonti, A. D., Babbar-Sebens, M., \& Jane Luzar, E. (2013). Optimizing conservation practices in watersheds: Do community preferences matter?: Optimizing Conservation Practices. Water Resources Research, 49(10), 6425-6449. doi:10.1002/wrcr.20491

Poiani, K. A., \& Johnson, W. C. (1991). Global Warming and Prairie Wetlands. BioScience, 41(9), 611-618. doi:10.2307/1311698

Poiani, K. A., Johnson, W. C., \& Kittel, T. G. F. (1995). Sensitivity of a Prairie Wetland to Increased Temperature and Seasonal Precipitation Changes1. JAWRA Journal of the American Water Resources Association, 31(2), 283-294. doi:10.1111/j.17521688.1995.tb03380.x

Rojas, R., Feyen, L., Dosio, A., \& Bavera, D. (2011). Improving pan-European hydrological simulation of extreme events through statistical bias correction of RCM-driven climate simulations. Hydrology and Earth System Sciences, 15(8), 2599-2620. doi:10.5194/hess15-2599-2011

Rupp, D. E., Abatzoglou, J. T., Hegewisch, K. C., \& Mote, P. W. (2013). Evaluation of CMIP5 20th century climate simulations for the Pacific Northwest USA. Journal of Geophysical Research: Atmospheres, 118(19), 2013JD020085. doi:10.1002/jgrd.50843

Salathé, E. P. (2003). Comparison of various precipitation downscaling methods for the simulation of streamflow in a rainshadow river basin. International Journal of Climatology, 23(8), 887-901. doi:10.1002/joc.922

Schmidli, J., Frei, C., \& Vidale, P. L. (2006). Downscaling from GCM precipitation: a benchmark for dynamical and statistical downscaling methods. International Journal of Climatology, 26(5), 679-689. doi:10.1002/joc.1287 
Servat, E., \& Dezetter, A. (1991). Selection of calibration objective functions in the context of rainfall-runoff modelling in a Sudanese savannah area. Hydrological Sciences Journal, 36(4), 307-330.

Terink, W., Hurkmans, R., Torfs, P., \& Uijlenhoet, R. (2009). Bias correction of temperature and precipitation data for regional climate model application to the Rhine basin. Hydrology \& Earth System Sciences Discussions, 6(4). Retrieved from http://search.ebscohost.com/login.aspx?direct=true\&profile=ehost\&scope=site\&authtype $=$ crawler $\&$ jrnl $=18122108 \& A N=45562293 \& \mathrm{~h}=$ LoIyLX\%2F082mA\%2B1X7Tk5odvvYb bP\%2BrepcUsw9TY3xZUcra293bT8vhTEDmDPc0qyT\%2Bfw6dUr9\%2FZbbwls3eP62 WQ\%3D\%3D\&crl=c

Teutschbein, C., \& Seibert, J. (2010). Regional climate models for hydrological impact studies at the catchment scale: a review of recent modeling strategies. Geography Compass, 4(7), 834-860.

Teutschbein, C., \& Seibert, J. (2012). Bias correction of regional climate model simulations for hydrological climate-change impact studies: Review and evaluation of different methods. Journal of Hydrology, 456-457, 12-29. doi:10.1016/j.jhydrol.2012.05.052

Thom, H. C. (1958). A note on the gamma distribution. Monthly Weather Review, 86(4), 117122.

U.S. Global Change Research Program. (2014). U.S. Global Change Research Program. Operated by the University Corporation for Atmospheric Research (UCAR). Retrieved from http://www.globalchange.gov/

Watkins Jr, D. W., \& McKinney, D. C. (1997). Finding robust solutions to water resources problems. Journal of Water Resources Planning and Management, 123(1), 49-58.

Whitfield, P. H., Wang, J. Y., \& Cannon, A. J. (2003). Modelling future streamflow extremesfloods and low flows in Georgia basin, British Columbia. Canadian Water Resources Journal, 28(4), 633-656.

Wilson, D. A. (2009). HURRICANE IKE AND IMPACT OF LOCALIZED FLOODING IN ST. LOUIS COUNTY, SEPTEMBER 14, 2008. Finding the Balance between Floods, Flood Protection, and River Navigation, Published by Saint Louis University, 22.

Winter, T. C. (2000). The Vulnerability of Wetlands to Climate Change: A Hydrologic Landscape Perspective1. JAWRA Journal of the American Water Resources Association, 36(2), 305-311. doi:10.1111/j.1752-1688.2000.tb04269.x

Zedler, J. B. (2003). Wetlands at your service: reducing impacts of agriculture at the watershed scale. Frontiers in Ecology and the Environment, 1(2), 65-72. 